UNIVERSITÀ CATTOLICA DEL SACRO CUORE

Dipartimento di Economia e Finanza

\author{
Working Paper Series
}

Animal Spirits, Heterogeneous Expectations and the Emergence of Booms and Busts

Tiziana Assenza

William A. Brock

Cars H. Hommes

Working Paper n. 7

December 2013

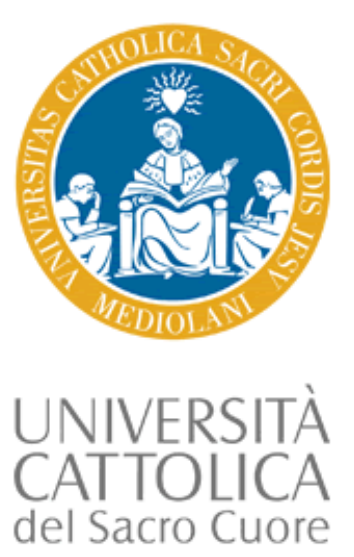




\title{
Animal Spirits, Heterogeneous Expectations and the Emergence of Booms and Busts
}

\author{
Tiziana Assenza \\ Università Cattolica del Sacro Cuore \\ William A. Brock \\ University of Wisconsin \\ Cars H. Hommes \\ University of Amsterdam
}

Working Paper n. 7

December 2013

\author{
Dipartimento di Economia e Finanza \\ Università Cattolica del Sacro Cuore \\ Largo Gemelli 1 - 20123 Milano - Italy \\ tel: +39.02.7234.2976 - fax: +39.02.7234.2781 \\ e-mail: dip.economiaefinanza@unicatt.it
}

The Working Paper Series promotes the circulation of research results produced by the members and affiliates of the Dipartimento di Economia e Finanza, with the aim of encouraging their dissemination and discussion. Results may be in a preliminary or advanced stage. The Dipartimento di Economia e Finanza is part of the Dipartimenti e Istituti di Scienze Economiche (DISCE) of the Università Cattolica del Sacro Cuore. 


\title{
Animal Spirits, Heterogeneous Expectations and the Emergence of Booms and Busts*
}

\author{
Tiziana Assenza ${ }^{\mathrm{a}, \mathrm{b}}$ William A. Brock ${ }^{\mathrm{c}, \mathrm{d}}$ Cars H. Hommes ${ }^{\mathrm{b}, \mathrm{e}}$ \\ a Department of Economics and Finance, Università Cattolica del Sacro Cuore, Milano, \\ b Amsterdam School of Economics, University of Amsterdam, CeNDEF, \\ ${ }^{\mathrm{c}}$ University of Wisconsin, Madison, ${ }^{\mathrm{d}}$ University of Missouri, Columbia, \\ e Tinbergen Institute, Amsterdam
}

First Draft: May, 2009

This Draft: December, 2013

\begin{abstract}
We introduce a simple equilibrium model of a market for loans, where households lend to firms based on heterogeneous expectations about their loan default probability. Agents select among heterogeneous expectation rules, based upon their relative performance. A small fraction of pessimistic traders already has a large aggregate effect, leading to a crisis characterized by high contract rates for loans and low output. Our stylized model illustrates how animal spirits and heterogeneous expectations amplify boom and bust cycles and how endogenous coordination on pessimistic expectations amplifies crises and slows down recovery. Taking heterogeneous expectations and bounded rationality into account is crucial for the timing of monetary or fiscal policy.
\end{abstract}

JEL codes: E32, D83, D84

Keywords: Heterogeneous Expectations, Crises, Animal Spirits.

\footnotetext{
*Tiziana Assenza: e-mail: tiziana.assenza@unicatt.it; address: Università Cattolica del Sacro Cuore, Largo Gemelli, 1, 20123 Milano, Italy; phone number: +390272342483.

Cars Hommes: e-mail: C.H.Hommes@uva.nl; address: CeNDEF, Department of Quantitative Economics, University of Amsterdam Valckenierstraat 65-67, 1018 XE Amsterdam, The Netherlands; phone number: +31205254246.

William Brock: e-mail: wbrock@ssc.wisc.edu; address: Economics Department, University of Wisconsin - Madison 1180 Observatory Drive Madison, WI 53706.
} 
Acknowledgments: Earlier versions of this paper, under the title Animal Spirits, Heterogeneous Expectations and the amplification and duration of crises have been presented at the conference "Rethinking Economic Policies in a Landscape of Heterogeneous Agents", Università Cattolica del Sacro Cuore, Milano, October 13-15, 2011; the workshop "Complex Systems: Towards a Better Understanding of Financial Stability and Crises" De Nederlandsche Bank, Amsterdam, November 3-4, 2011; the workshop of the International Network on Expectational Coordination (INEXC), June 27-29, 2012, Paris; the AEA meetings, San Diego, January 4-6, 2013; the Research Seminar series at the De Nederlandsche Bank, Amsterdam, January 22, 2013; the EEA-ESEM meetings, Gothenburg, August 26-30, 2013; the $19^{\text {th }}$ International Conference "Computing in Economics and Finance", July 10-12, 2013, Vancouver and the "OFCE-SKEMA-GREQAM Workshop on Agent-Based Macroeconomics", November 22, 2013, Sophia Antipolis, Nice. We would like to thank participants for useful comments and discussions. Financial support from the Netherlands Organization for Scientific Research (NWO), project "Understanding Financial Instability through Complex Systems"; the EU 7th framework projects "Complexity Research Initiative for Systemic InstabilitieS (CRISIS)", grant no. 288501 and "Macro-Risk Assessment and Stabilization Policies with New Early Warning Signals (Rastanews)" grant no 320278; the Unicredit \& Universities Post doc Grant project "Animal Spirits and Financial Crises"; University of Wisconsin Department of Economics and from the Vilas Trust are gratefully acknowledged. None of the above are responsible for errors in this paper. 


\section{Introduction}

In their book Akerlof and Shiller (2009) stressed the importance of "animal spirits" for the origin and propagation of a financial-economic crisis, for the subsequent recession and for the "exit" process from the recession. They discuss recent advances in behavioral economics in order to identify different types of "animal spirits", with "confidence" being one of the cornerstone animal spirits. Akerlof and Shiller point to an important problem facing economics: "confidence" shares with "financial factors" the fate of being difficult to conceptualize, model, and measure. The present paper is essentially an attempt to build a dynamic equilibrium model of agents' confidence. We introduce a simple dynamic equilibrium model for loanable funds, and show how a sudden collapse of confidence may, on the one hand, accelerate and amplify the downturn of an economy after a negative shock, and, on the other hand, slow down the recovery from an economic crisis. The core ingredient of our model is the crucial role we assign to expectations' heterogeneity and, especially how endogenous selection of heterogeneous expectation rules based on their relative performance feeds into the dynamics of wages, output and the dynamics of contracting terms that the lending side of the economy imposes on the borrowing side of the economy in dynamic equilibrium. Endogenous selection of pessimistic expectations in bad times may then lead to coordination on pessimism, thus amplifying a crisis and slowing down recovery ${ }^{1}$.

It is almost a commonplace that the behavior of a variable in the aggregate - i.e. at the macroeconomic level - does not necessarily correspond to the behavior of the same variable as decided at the microeconomic level by a "representative" individual: "Any meaningful model of the macroeconomy must analyze not only the characteristics of the individuals but also the structure of their interactions" (Colander et al., 2008, p.237). Arrow also stressed the key role of heterogeneous expectations for modeling the economy: "One of the things that microeconomics teaches you is that individuals are not alike. There is heterogeneity, and probably the most important heterogeneity here is heterogeneity of expectations. If we didn't have heterogeneity, there would be no trade. But developing an analytic model with heterogeneous agents is difficult." (Ken Arrow, In: Colander et al., 2004, p.301). The emergent macro behavior in our model driven by endogenous interactions of heterogeneous expectations includes amplification of persistent boom and bust cycles.

In behavioral modeling of animal spirits and confidence, bounded rationality plays a key role. In macroeconomics in the last two decades much work has already been done on bounded rationality and adaptive learning; see e.g. Sargent, (1993) and Evans and Honkapohja, (2001), for extensive discussions. In the adaptive learning literature, the representative agent assumption is still the workhorse of contemporary models. More-

\footnotetext{
${ }^{1}$ We recently found the interesting paper by Mamatzakis (July, 2013), that reports empirical evidence that market level pessimism has important effects and that substantial elements of the market may not share common preferences/beliefs.
} 
over most attention has focussed on cases where the learning process ends with the discovery of the "true model" of the economy, thus confirming rational expectations ex post. More recently a number of macro models with heterogeneous expectations have been introduced, e.g. Brock and de Fontnouvelle (2000), Evans and Honkapohja (2003, 2006), Berardi (2007) and Assenza and Berardi (2009)2 . We will use the heterogeneous expectations framework of Brock and Hommes $(1997,1998)$, where agents are boundedly rational and switch between different expectations rules based upon their relative success $^{3}$. Branch and Evans (2006), Branch and McGough (2009), Lines and Westerhoff (2010), Anufriev et al. (2013a), Brazier et al. (2008) and DeGrauwe (2011) have applied this heterogeneous expectations framework in various macro-economic settings. Cornea et al. (2013) recently estimated a heterogeneous expectations model with forward looking fundamentalists versus backward looking naive expectations to US-inflation data.

There is quite some empirical evidence for the persistence of heterogeneity in expectations, both in survey data and in laboratory experiments. For example, Mankiw et al. (2003), Branch (2004) and Pfajfar and Santoro (2010) provided empirical evidence in support of heterogeneous expectations using survey data on inflation expectations. Expectations heterogeneity in experimental data is found e.g. in Hommes et al. (2005a), Adam (2007) and Pfajfar and Zakelj (2011). Assenza et al. (2013), Anufriev and Hommes (2012) and Roos and Luhan (2012) find evidence for performance based switching between forecasting rules in laboratory experiments; see Duffy (2008) and Hommes (2011) for an overview of experimental work in macro.

In order to model the Akerlof-Shiller "animal spirits" and "confidence", we apply the Brock-Hommes heterogeneous expectations framework to a dynamic equilibrium model of loanable funds. We abstract from the complexity of the real world contract terms for a loan by using a one-dimensional proxy variable that we call the "contract rate". The reader should think of a contract rate not only as a measure of the interest rate for the loan, but more generally of "qualification adjusted contract terms" describing today's difficulties of getting a loan, e.g. by raising credit score qualifications, increasing down payment requirements for the loan, etc.

We borrow from recent work by Brock and Manski (2008, 2011), (B\&M hereafter) to describe and conceptualize ambiguity and pessimism in a credit market economy. In particular B\&M take into account the existence in credit markets of an informational problem due to partial knowledge of loan repayments, i.e. lenders do not know a priori

\footnotetext{
${ }^{2}$ More recently, Evans et al. (2008) and Benhabib et al. (2012) study the NK model under learning with an interest-rate rule subject to a lower bound. Large pessimistic shocks to expectations can lead to deflationary spirals with falling prices and falling output. To avoid this outcome Evans et al. (2008) recommend augmenting normal policies with aggressive monetary and fiscal policy guaranteeing a lower bound on inflation

${ }^{3}$ Simsek (2013) and Scheinkman and Xiong (2003) have stressed the role of overly optimistic (over confident) believers in driving bubble like phenomena in a framework where rational agents take into account the presence of overly optimistic believers, but without endogenous strategy selection. Our model contains rational as well as boundedly rational agents; see Hommes (2006) for an overview and extensive discussion of heterogeneous expectations and bounded rationality.
} 
whether a borrower will totally repay his debt or only part of it, or, in the worst case scenario, he will not repay at all. In B\&M lenders must build a model of borrower behavior, which they are unable to completely specify due to lack of knowledge. We assume that most lenders lack fully rational expectations in forming expectations about the future share of loans that will be paid back. While B\&M use a static model, we study the role of expectations in a dynamic equilibrium model for loanable funds driven by an exogenous stochastic process for the probability that loans will be paid back. We deviate from rational expectations by considering a model with heterogeneous, boundedly rational expectations. In particular, we replace rational expectations with heterogeneous types of expectational schemes, including rational, naive, average, trend following and pessimistic expectations. As in Brock and Hommes $(1997,1998)$, agents select among forecasting rules, depending upon the relative success of each rule in predicting the loan default probability.

The presence of non-rational expectations and heterogeneity will play an important role when the credit market experiences an unexpected negative shock. A key observation of our paper is that heterogeneity in expectations and the presence of pessimistic agents, even when their fraction is relatively small, has a significant and persistent aggregate effect. Indeed, even a small fraction of pessimistic traders may cause a significantly higher contract rates in the loan market and significantly lower wages and output. Heterogeneity in expectations affects both the magnitude of a crisis and the speed of recovery from a crisis. More precisely, endogenous selection among heterogeneous expectation rules may enforce coordination on pessimistic expectations and a significant increase of the contract rates for loans, a subsequent decline of lending, wages and output and a slowdown of the recovery from an economic crisis.

The present paper is closely linked to the "confidence" "Animal Spirits" of Akerlof and Shiller (2009), because we introduce a measure of confidence, represented by the lender's expectation about the borrower's probability of success, i.e. the probability to repay the loan. In fact, we can interpret the probability of success as a measure of optimism about the share of borrowers that will be solvent. In other words the higher the expectation of the probability of success the higher the lender's confidence that tomorrow the borrower will reimburse the loan (and vice versa). We view our paper as moving a step ahead introducing the endogenous role of heterogeneous expectations in building an explicit stylized dynamic model of (part of) Akerlof and Shiller's conceptual framework of animal spirits and confidence to model economic crises. This enables us to study the way in which heterogeneity affects the path towards recovery after a negative shock to the economy. In particular we find that a snap collapse of confidence, due to an unanticipated negative shock, in the presence of heterogeneous agents, may amplify a downturn and may keep the economy in a recession phase for a longer period than in the case of a representative rational agent. To put it in another way we show how different individual expectational schemes on "confidence" impact the aggregate 
dynamics of output and contract terms in our model.

The paper is organized as follows. Section 2 introduces the modeling framework describing households and firms and the dynamic equilibrium. In Section 3 we consider a number of homogeneous expectations benchmarks, including rational, naive, average, trend following, optimistic (maximum) and pessimistic (minimum) expectations. Section 4 focuses on heterogeneous expectations and Section 5 presents a 6-type example collecting all previous homogeneous rules. In section 6 we endogenize the probability of success with positive feedback from the state of the the economy, i.e. output. Finally, Section 7 concludes.

\section{The model}

This section describes the basic ingredients of our framework. We consider a market for loanable funds that is populated by households/lenders and firms/borrowers. The households' sector, which also represents the supply side of the market for loanable funds, is built by means of an overlapping generations framework in which each agent when young consumes $\left(c_{t, t}\right)$ and saves earnings $\left(s_{t}\right)$ from work, with wages $w_{t}$. Savings are invested either in a safe asset or in a risky asset (productive investment). When old the agent consumes $\left(c_{t, t+1}\right)$ an endowment $\left(\omega_{o}\right)$ and the average return on investments.

The demand side of the market for loanable funds in our economy is represented by firms that borrow a certain amount of capital $\left(x_{t}\right)$ for production and remunerate work after paying back their debt. The remuneration for work is used by households to consume and to save. Savings are used to extend loans to the firms' sector.

\subsection{Households}

The supply side of our economy is described by means of a two-period overlapping generations structure. We assume that the young agent at date $t$ has preferences defined over consumption when young $c_{t, t}$ and when old $c_{t, t+1}$. For the sake of convenience, we assume a logarithmic utility function. The objective function therefore is

$$
u_{t}=\ln c_{t, t}+\ln c_{t, t+1}^{e}
$$

where $c_{t, t+1}^{e}$ is expected consumption when old. When young, the agent works and earns a real wage $w_{t}$ (i.e. wages from the productive sector). He invests his savings $s_{t}$ partly in a safe asset, which yields a known fixed return $\rho$ at $t+1$, and partly in a risky asset whose rate of return $\lambda_{t+1}$ in period $t+1$ is uncertain. Investment in the risky asset can be conceived of as employment of resources ("capital") in the productive sector, whose output is uncertain. The expectations by the young formed at date $t$ on the return of the risky asset at date $t+1$ are denoted by $\lambda_{t+1}^{e}$. When old, the agent retires and receives an (exogenous) endowment $\omega_{o}$ (at the beginning of old age) and the return on asset 
investments. The budget constraint of the agent when young and when old respectively, therefore, are

$$
\begin{aligned}
c_{t, t} & \leq w_{t}-s_{t}, \\
c_{t, t+1}^{e} & \leq \omega_{o}+s_{t}\left[\left(1-\delta_{t}\right) \rho+\delta_{t} \lambda_{t+1}^{e}\right]
\end{aligned}
$$

where $w_{t}$ is labour income. The decision problem of the young is to optimize (2.1) subject to (2.2) and (2.3). At date $t$ the young agent decides real savings $s_{t}$ and allocates a fraction $\delta_{t}$ to the risky asset which he anticipates to produce a real amount $s_{t} \delta_{t} \lambda_{t+1}^{e}$ available for consumption in $t+1$. Therefore $s_{t} \delta_{t} \lambda_{t+1}^{e}$ can be interpreted as expected production obtained employing $s_{t} \delta_{t}$ in the productive sector. It follows that $\lambda_{t+1}^{e}$ can be interpreted as the expected average productivity of capital in this context. The amount $s_{t}\left(1-\delta_{t}\right)$ allocated at date $t$ to the safe asset is known by the young at date $t$ to produce $s_{t}\left(1-\delta_{t}\right) \rho$ available for consumption in period $t+1$. The expression in brackets in $(2.3)$ i.e.,

$$
\mu_{t+1}^{e}=:\left(1-\delta_{t}\right) \rho+\delta_{t} \lambda_{t+1}^{e}
$$

will be denoted as the expected average return on investment. Substituting the constraints into the objective function one ends up with the following maximization problem

$$
\max _{s t} \ln \left(w_{t}-s_{t}\right)+\ln \left(\omega_{0}+s_{t} \mu_{t+1}^{e}\right)
$$

The FOC gives the following expression for savings

$$
s_{t}=\frac{1}{2}\left(w_{t}-\frac{\omega_{o}}{\mu_{t, t+1}^{e}}\right) .
$$

Assuming, for the sake of simplicity, zero endowment when old i.e., $\omega_{o}=0$, the FOC simplifies to

$$
s_{t}=\frac{w_{t}}{2}
$$

Note that (2.7) says that, conditional on $w_{t}$, the supply for investment, i.e. the total amount of savings $s_{t}$, is perfectly inelastic w.r.t. known and unknown returns on assets next period. How these savings will be distributed over the risk free and the risky asset will be discussed in subsection 2.3.

\subsection{Firms' demand for loanable funds}

Following Brock and Manski $(2008,2011)$ we assume that borrowers get into debt in order to finance productive investments. Moreover, if returns on investments turn out to be too low, they may not be able to pay back. Therefore, we introduce a (time varying) probability of success, $p_{t}$ or, equivalently, a probability of bankruptcy $1-p_{t}$. The 
probability of success represents the share of firms that will be able to pay back their loans. Firms choose the amount of capital $x_{t}$, borrowed from the lending side of the economy, at time $t$ solving the maximization problem:

$$
\max _{x_{t}}\left\{p_{t}\left(g\left(x_{t}\right)-r_{t} x_{t}\right)+\left(1-p_{t}\right)\left(-r_{t} x_{t}\right)\right\}=\max _{x_{t}}\left\{p_{t} g\left(x_{t}\right)-r_{t} x_{t}\right\}
$$

where $r_{t}>1$ is the gross "contract rate" (i.e. the "rental rate" on capital) and $g\left(x_{t}\right)$ is the production function, assumed to be strictly concave with decreasing returns to scale ${ }^{4}$. Here "contract rate" is a "proxy" for the general contract terms describing how difficult it is to get a loan. A higher contract rate does not necessarily mean a higher interest rate for the loan, but also reflects an increase of the general qualifications to obtain a loan, such as raising credit score qualifications, increasing down payment requirements, etc. The maximization problem yields the following FOC:

$$
p_{t} g^{\prime}\left(x_{t}\right)=r_{t} \Longrightarrow x_{t}=x\left(r_{t} ; p_{t}\right)=g^{\prime-1}\left(\frac{r_{t}}{p_{t}}\right) \text {. }
$$

Given the features of the production function $g\left(x_{t}\right)$, equation (2.9) represents a decreasing relation between the amount of capital at period $t$ and the rental rate on capital in the same period, therefore it defines the demand for capital in this setting. We can define the returns to the "other factor" (i.e. labor) besides factor $x$ as a function of the amount of factor $x$ hired. In other words what is left over after overheads and capital are paid goes to other factors and the bulk of other factors are types of labor. Hence wages from the productive sector at time $t$ can be defined as:

$$
w_{t}:=p_{t-1} g\left(x_{t-1}\right)-r_{t-1} x_{t-1}=p_{t-1} g\left(x_{t-1}\right)-p_{t-1} g^{\prime}\left(x_{t-1}\right) x_{t-1},
$$

where the last equality obtains from substituting eq. (2.9). In the case of a Cobb Douglas production function $g\left(x_{t}\right)=x_{t}^{\alpha}$, where $0<\alpha<1$ represents the capital's share, (2.9) and (2.10) specialize to the demand function and wages given by

$$
\begin{aligned}
& x_{t}=x\left(r_{t} ; p_{t}\right)=\left(\frac{r_{t}}{p_{t} \alpha}\right)^{\frac{1}{\alpha-1}}, \\
& w_{t}=p_{t-1}(1-\alpha) x_{t-1}^{\alpha} .
\end{aligned}
$$

Substituting the demand for capital $x_{t}$ from (2.11) into (2.12) we get the labor income in the case of Cobb Douglas production function

$$
w_{t}=\eta\left(p_{t-1}\right)^{\frac{1}{1-\alpha}} r_{t-1}^{\frac{\alpha}{\alpha-1}}
$$

where $\eta=\alpha^{\frac{\alpha}{1-\alpha}}(1-\alpha)$. Since lenders get zero under bankruptcy and consequently wages for bankrupt firms are zero it follows that (2.13) represents wages paid by successful firms

\footnotetext{
${ }^{4}$ More precisely, we assume $g^{\prime}\left(x_{t}\right)>0, g^{\prime \prime}\left(x_{t}\right)<0$ with right hand and left hand Inada conditions i.e., $g(0)=0, g^{\prime}(0)=\infty, g^{\prime}(\infty)=0$.
} 
at time $t$. For later use it will also be useful to define the inverse demand function as

$$
r_{t}=r\left(x_{t} ; p_{t}\right)=\alpha p_{t} x_{t}^{\alpha-1}
$$

\subsection{Equilibrium}

In this subsection we will compute the equilibrium of our economy. Following Brock and Manski $(2008,2011)$, we indicate with $x_{j}\left(r_{t}\right)$ the $j$-th borrower's loan demand at a contract rate $r_{t}$. Hence for a "sample" of $J$ firms the lender's expected loan return is given by

$$
\lambda_{t+1}^{e}\left(r_{t}\right)=\frac{\frac{1}{J} \sum_{j=1}^{J} \min \left\{\imath\left(j \in S_{t}\right) g\left(x_{j, t}\right), r_{t} x_{j, t}\right\}}{\frac{1}{J} \sum_{j=1}^{J} x_{j, t}}
$$

where $\imath\left(j \in S_{t}\right)$ is the indicator function which is unity if firm $j$ is successful at date $t$ and is zero otherwise. Moreover the numerator represents aggregate repayment and the denominator aggregate loan demand. We assume success is independently distributed across firms at each date $t$. Therefore, firm $j$ chooses $x_{j, t}$ to satisfy:

$$
x_{j, t}=\max _{x_{j, t}}\left\{p_{j, t} g\left(x_{j, t}\right)-r_{t} x_{j, t}\right\}
$$

provided that the maximized quantity is nonnegative, otherwise firm $j$ shuts down and does not operate in period $t$, that is, it chooses $x_{j, t}=0$.

Assume that the probability of success is the same for all firms at date $t$, i.e. $p_{j, t} \equiv p_{t}$, for all $j$. Then each firm solves the same maximization problem and the optimal solution is the same for all firms. Apply the Law of Large Numbers to Eq. (2.15) to obtain the "population" loan return function:

$$
\lambda_{t+1}^{e}\left(r_{t}\right)=p_{t+1}^{e} r_{t}
$$

where $p_{t+1}^{e}$ is the expected probability of success, that is, the share of firms that is expected to be able to pay back the loan. The expected probability of success may be seen as a measure of "confidence" in our economy. Assuming risk neutrality, the no arbitrage condition is such that the return on the risky asset equals the return on the risk free investment i.e., $\lambda_{t}=\rho$. It follows that the no arbitrage value of the contract rate $\left(r_{t}^{*}\right)$ is given by the following relation

$$
r_{t}^{*}=\frac{\rho}{p_{t+1}^{e}}
$$

At this stage we have all the necessary ingredients to compute the equilibrium of our 


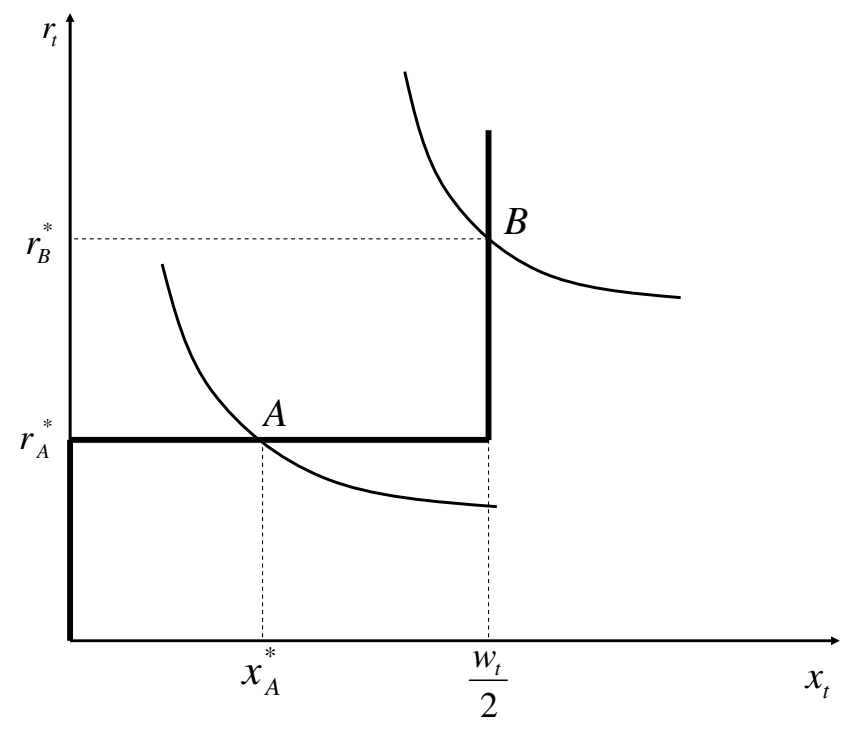

Figure 1: The loan supply correspondence (2.20) and the demand curve (2.9). Points A and $\mathrm{B}$ represents the two possible configurations of the temporary equilibrium allocations $\left(x^{*}, r^{*}\right)$ depending on the time varying features of the demand and supply curves.

model. Let us define

$$
\Delta_{t}^{*}\left(r_{t}\right):=\bar{\imath}\left[r_{t}>\frac{\rho}{p_{t+1}^{e}}\right]:=\bar{\imath}\left[r_{t}>r_{t}^{*}\right]
$$

where the upper bar over the indicator function means that it is the set $[0,1]$ when $=$ holds instead of $>$. Hence we can define the loan supply correspondence, when old age endowment $\omega_{o}$ is zero, by

$$
S_{t}\left(r_{t}\right):=\frac{w_{t}}{2} \bar{\imath}\left[r_{t}>r_{t}^{*}=\frac{\rho}{p_{t+1}^{e}}\right]
$$

that is, when $r_{t}>r_{t}^{*}\left(r_{t}<r_{t}^{*}\right)$ all savings are invested into loans (the risk free asset). Note that it is the belief $p_{t+1}^{e}$ formed at date $t$ about the probability of success in $t+1$ that determines the loan supply at time $t$.

The demand for capital and the equilibrium value for the contract rate are determined by market clearing, i.e.

$$
x\left(r_{t} ; p_{t}\right)=S_{t}\left(r_{t}\right)
$$

Since the supply correspondence is a (time varying) step function, there are two possibilities for the equilibrium, points $A$ and $B$, as illustrated in Figure 1. 
The first possibility for equilibrium (point $A$ ) is given by

$$
\begin{aligned}
r_{A}^{*} & =\frac{\rho}{p_{t+1}^{e}} \\
x_{A}^{*} & =x\left(r_{A}^{*} ; p_{t}\right)=\left(\frac{\rho}{\alpha p_{t} p_{t+1}^{e}}\right)^{\frac{1}{\alpha-1}},
\end{aligned}
$$

arising when $x\left(r_{A}^{*} ; p_{t}\right)<w_{t} / 2$, where $x(\cdot)$ is the demand function (2.11).

The other possibility (point $B$ ) is given by

$$
\begin{aligned}
& r_{B}^{*}=r\left(x_{B}^{*} ; p_{t}\right)=\alpha p_{t}\left[\frac{1}{2}\left(p_{t-1}\right)^{\frac{1}{1-\alpha}} r_{t-1}^{\frac{\alpha}{\alpha-1}} \eta\right]^{(\alpha-1)} \\
& x_{B}^{*}=\frac{w_{t}}{2}=\frac{1}{2}\left(p_{t-1}\right)^{\frac{1}{1-\alpha}} r_{t-1}^{\frac{\alpha}{\alpha-1}} \eta
\end{aligned}
$$

and it arises when $x\left(r_{A}^{*} ; p_{t}\right)>w_{t} / 2$.

It is important to note the crucial role played by expectations on the firms' probability of success $\left(p_{t+1}^{e}\right)$, the confidence measure in our economy. In fact, given the return on the risk free asset, the lower the expected probability of success the higher will be the non arbitrage contract rate $\left(r_{t}^{*}\right)$ and, consequently, the lower will be the demand for capital $\left(x_{t}^{*}\right)$. On the other hand, a high expected probability of success $p_{t+1}^{e}$ causes the contract equilibrium rate $r_{A}^{*}$ to drop. Hence, optimistic expectations amplify a boom (low contract rate and high output), while pessimistic expectations amplify a bust or crisis of the economy (high contract rate and low output).

\section{Homogeneous beliefs}

We have not yet specified the probability of success $p_{t}$ and how lenders form expectations about this probability to repay the loan. We are particularly interested in the situation where there is a series of "bad" exogenous shocks to the economy and the probability of success suddenly drops. Instead of focussing on a single stochastic negative shock and an impulse response analysis, we assume an exogenous dynamic stochastic process for the probability of success and then study the corresponding equilibrium dynamics. We focus on the simple case of an exogenous $\operatorname{AR}(1)$ process for the probability of success, given by

$$
p_{t+1}=\mu+a\left(p_{t}-\mu\right)+\epsilon_{t},
$$

where $\mu$ is the long run average, $a$ is the first order autocorrelation coefficient and $\epsilon_{t}$ is an IID random variable drawn from a normal distribution. Throughout the paper we fix $\mu=0.95, a=0.8$ and $\sigma=0.01$, so that the (long run) average is 0.95 and there is some persistence in the probability of success. In all dynamic simulations in this paper the realizations of the noise $\epsilon_{t}$ are the same and the exogenous probability time series 
is as illustrated in Figure 2 (top panels). The success probability fluctuates between 0.899 and 0.969 over 100 periods. Between periods 20 and 30, the probability gradually declines to hit its lowest value 0.899 in period 31 . We will refer to this lowest value as the "crisis" due to the exogenous shocks. Our main interest here is how confidence, that is, expectations about the probability of success, affects temporary equilibrium dynamics of contract rates, wages and output, and in particular, what happens after the exogenously generated crisis under heterogeneous expectations.

Before investigating the role of heterogeneous expectations, by way of comparison it is useful to consider a number of benchmark specifications of the lender's expectations in the simple case of a representative agent, i.e. we will consider some homogeneous expectations benchmarks. In addition to the standard rational expectations view, we allow for bounded rationality and consider a number of benchmark cases with a simple forecasting rule. Hey (1994) showed that in laboratory experiments where individuals forecast an exogenous stochastic $\mathrm{AR}(1)$ time series, rational expectations is rejected in most cases and simple forecasting rules such as adaptive expectations provide a better description of individual forecasting behavior; see also Dwyer et al. (1993). In more recent learning to forecast laboratory experiments simple forecasting rules, such as naive expectations or a trend following rule, as described below, fit individual forecasting behavior quite nicely, see e.g. the survey in Hommes (2011).

\subsection{Rational expectations}

In the case of rational expectations, lenders are assumed to have perfect knowledge about the true stochastic probability process. Agents know that the probability of success follows the $\mathrm{AR}(1)$ process (3.1) with perfect knowledge about its parameters. The rational forecast of the probability of success at period $t+1$ is given by

$$
p_{t+1}^{e}=\mu+a\left(p_{t}-\mu\right)
$$

Figure 2a illustrates time series of the realized probability $p_{t}$, the rational $\operatorname{AR}(1)$ forecast, and the equilibrium contract rate $r_{t}$. The rational forecast closely tracks the realized probability and the contract rate spikes exactly in the crisis period 31 when the probability of success hits its lowest value or, equivalently, when the probability of default hits its highest value. Under rational expectations, the dynamics of the contract rates is characterized by mean reversion to its long run equilibrium value $\bar{r}=\rho / \mu=(1.01 / 0.95) \approx 1.063^{5}$, with exactly the same speed as the exogenous true probability process.

\footnotetext{
${ }^{5}$ Where $\rho$ is the risk free rate of return and $\mu$ is the long run mean of the $\operatorname{AR}(1)$ stochastic probability process.
} 

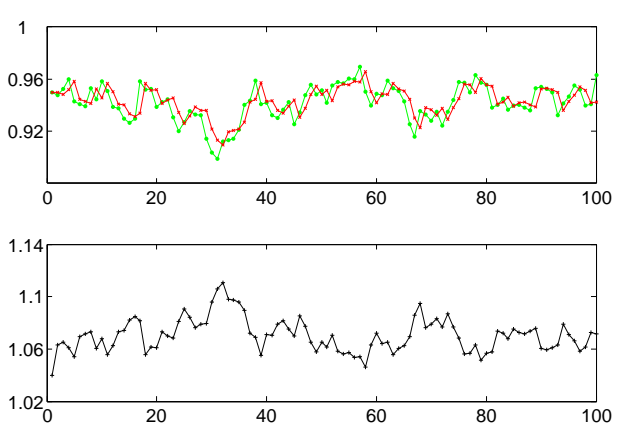

(a) Rational
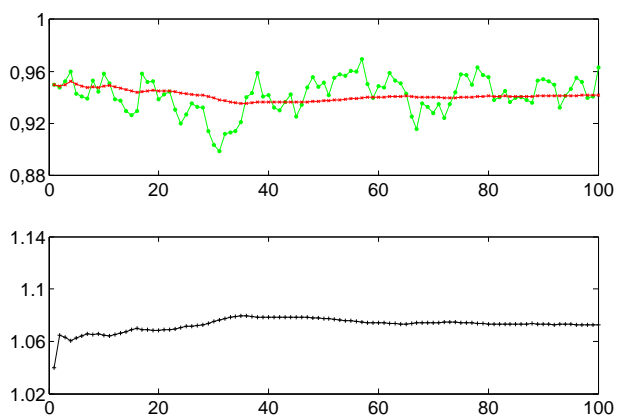

(c) Average
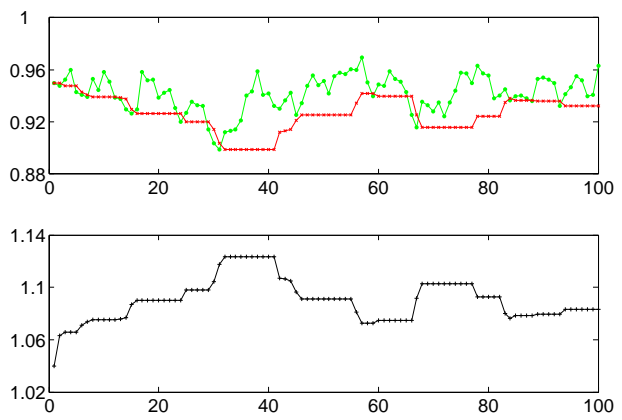

(e) Minimum
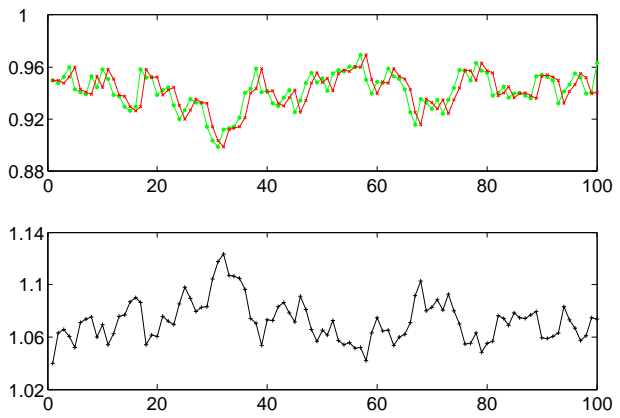

(b) Naive
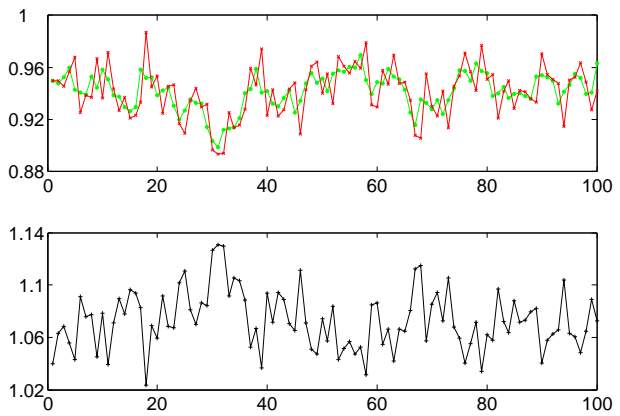

(d) Trend Follower
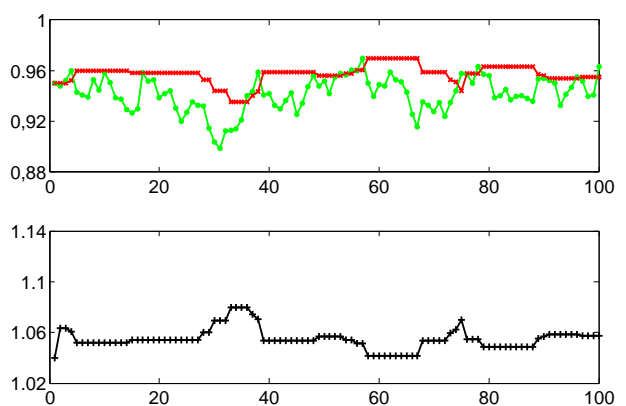

(f) Maximum

Figure 2: Homogeneous expectations benchmarks: (a) naive, (b) rational (AR1), (c) average, (d) trend follower, (e) pessimistic (minimum), and (f) optimistic (maximum). Top panels: realized (green) and expected (red) probability of success. Bottom panels: corresponding equilibrium contract rates $r_{t}$.

\subsection{Naive expectations}

Under naive expectations the forecast of the probability of success at period $t+1$ is given by last period's observation, i.e.,

$$
p_{t+1}^{e}=p_{t} .
$$


Figure $2 \mathrm{~b}$ illustrates time series of the realized probability $p_{t}$, the naive forecast and the equilibrium contract rate $r_{t}$. Clearly the naive forecast lags realized probability by one period and the contract rate spikes in period 32, immediately after the probability of success hits its lowest value in the "crisis-period" 31 (or equivalently the probability of default hits its highest value). The dynamics of the contract rate under naive expectations is characterized by mean reversion to its long run equilibrium value $\bar{r}=\rho / \mu=(1.01 / 0.95) \approx 1.063$. Under naive expectations, the dynamics of the contract rate $r_{t}$ is thus completely driven by the exogenous probability of success, just lagging one period behind. The speed of recovery of the economy after the exogenous crisis in period 31 is the same as the speed of mean reversion of the realized probability of success, and lags only one period behind the true probability. Notice that under naive expectations the peaks of the contract rate are more extreme, because the rational $\mathrm{AR}(1)$ rule correctly predicts mean reversion (on average) after an extreme observation, while naive expectations then uses the minimum (or maximum) observation.

\subsection{Average beliefs}

Another interesting case is when agents use long run averages in forecasting. In the case of average expectations, the forecast of the probability of success is given by the sample average of past observation, i.e.,

$$
p_{t+1}^{e}=\frac{1}{t+1} \sum_{i=0}^{t} p_{i} .
$$

Figure $2 c$ illustrates time series of the realized probability $p_{t}$, the average forecast and the equilibrium contract rate $r_{t}$. The average forecast adjusts slowly following realized probability and decreases gradually in the first 30 periods, until the probability of success hits its lowest value, in period 31. As a result, the contract rate slowly increases and slowly converges to its long run equilibrium level $\bar{r}=\rho / \mu \approx 1.063$. Hence, when all agents in the economy give equal weight to all past observations, the economy hardly fluctuates and slowly converges to its long run equilibrium steady state. Hence, average expectations smoothes or even prevents booms and busts.

\subsection{Trend following expectations}

In the case of trend following expectations the forecast of the probability of success is given by a simple linear extrapolation rule

$$
p_{t+1}^{e}=p_{t-1}+g\left(p_{t-1}-p_{t-2}\right)
$$

Simple trend following rules belong to the most popular rules used in learning to forecast laboratory experiments with human subjects (e.g. Hommes, 2011) and are also popular 
among chartists' trading rules in financial markets as has been documented in survey data analysis (e.g. Frankel and Froot, 1990, Allen and Taylor, 1990). Figure 2d illustrates time series of the realized probability $p_{t}$, the trend follower forecast (3.5) and the equilibrium contract rate $r_{t}$. Trend followers may lead to overly pessimistic or optimistic expectations, when the trend following forecast undershoots its minimum or overshoots its maximum realized value. As a consequence, this leads to more extreme spikes in the contract rate, e.g. higher maximum values of the contract rate in periods $32-33$, immediately following the exogenously generated crisis period 31, and lower minimum values of the contract rate, e.g. in period 18 following a high realized probability in period 17 and an extreme high forecast in period 18. Hence, the presence of trend followers amplifies booms and busts.

\subsection{Pessimistic expectations}

Now consider the homogeneous benchmark case of pessimistic expectations. We model pessimistic expectations by a forecast that predicts that the probability of success remains at its lowest observed value in the last $T$ periods, i.e.,

$$
p_{t+1}^{e}=\min \left\{p_{t+1-T}, p_{t+2-T}, \cdots, p_{t-1}, p_{t}\right\}
$$

As a typical example in the simulations below we choose $T=10$. Figure 2e illustrates time series of the realized probability $p_{t}$, the minimum forecast, together with the corresponding equilibrium contract rate $r_{t}$. The minimum forecast adjust according to the local minima of the observed probability and decreases until its lowest value in period 32 to stay there for 10 periods, after the probability of success hits its lowest value, in period 31. As a result, the contract rate increases gradually and hits its highest value in period 32 to stay there for 10 periods. Under pessimistic beliefs after each local minimum of the probability of success the contract rate spikes at a local maximum and stays there for at least $T=10$ periods or jumps to a new (local) maximum. Pessimistic expectations thus considerably slow down the mean reversion of the dynamic equilibrium process and therefore amplify the duration of an economic crises and slow down economic recovery.

\subsection{Optimistic expectations}

Finally consider the symmetrically opposity homogeneous benchmark case of what we call optimistic expectations, forecasting that the probability of success remains at its highest observed value in the last $T$ periods, i.e.,

$$
p_{t+1}^{e}=\max \left\{p_{t+1-T}, p_{t+2-T}, \cdots, p_{t-1}, p_{t}\right\}
$$

As for the pessimistic rule, in the simulations below we take $T=10$. Figure $2 \mathrm{f}$ illustrates time series of the realized probability $p_{t}$, the maximum forecast, together with the 
corresponding equilibrium contract rate $r_{t}$. When the probability of success hits high values, the maximum forecast adjusts according to the local maxima of the observed probability. This leads to persistently low values of the contract rate and an economic boom. For example, when the probability of success hits its highest value in period 57 , the optimistic forecast stays there for 10 periods, leading to the lowest contract rate in periods $58-67$. Optimistic expectations thus cause long lasting economic booms.

\section{Heterogeneous beliefs}

We extend our framework in order to take into account heterogeneity in agents' beliefs. In particular, we follow Brock and Hommes (1997) to model heterogeneous expectations by a discrete choice model and evolutionary strategy selection based on their relative past performance. There is quite some empirical evidence for heterogeneity of expectations and performance based strategy switching in various economic settings. For example, Branch $(2004,2007)$ estimates a simple switching model with heterogeneous expectations using exchange rate survey data, Vissing-Jorgensen (2003) presents evidence of heterogeneous beliefs of individual investors about the prospect of the stock market, and Shiller (2000) finds evidence that investor's sentiment changes over time, with both institutions and individual investors becoming more optimistic in response to recent significant increases of the stock market. Heterogeneous expectations switching models have been successfully estimated/calibrated in various empirical applications, for example, to explain bubbles and crashes in stock prices (e.g. Boswijk et al., 2007, Amilon, 2008, de Jong et al., 2009; Lof, 2012), large movements in exchange rates (e.g. Gilli and Winker, 2003, Westerhoff and Reitz, 2003), persistent high and low inflation (Cornea et al., 2012) and bubbles and crashes in commodities (e.g. gold prices Alfarano et al., 2005, and oil prices Ellen and Zwinkels, 2010). Anufriev and Hommes (2012) and Assenza et al. (2013) fitted a heuristics switching model to laboratory data of asset pricing and inflation/output forecasting experiments.

\subsection{Heterogeneous expectations}

Assume there are $J$ types of lenders in our economy. At date $t$, type j's forecast for period $t+1$ of the return on the risky asset is given by

$$
\lambda_{j, t+1}^{e}=p_{j, t+1}^{e} r_{t}
$$

Hence, each forecasting rule is determined by its forecast $p_{j, t+1}^{e}$ of the probability of success, i.e. the probability that the firm will pay back the loan. Agents can choose between $J$ different forecasting rules. The main idea underlying the switching model is that agents are boundedly rational and choose a forecasting strategy based upon its relative past performance. Let $U_{j, t}$ be a weighted average of past squared forecasting 
errors of type $j$ of the returns $\lambda_{j, t}$ which, using (4.1), becomes

$$
U_{j, t}=r_{t-1}^{2}\left(p_{t}-p_{j, t}^{e}\right)^{2}+\gamma U_{j, t-1}
$$

where $\gamma$ is the weight given to past fitness. Let $u_{j, t}$ be the relative past squared forecasting errors of the returns of the risky asset, that is,

$$
u_{j, t}=U_{j, t} / U_{t}^{t o t}, \quad U_{t}^{t o t}=\sum_{j=1}^{J} U_{j, t}
$$

The fraction of the expectations rule $j$ is updated according to a discrete choice model with asynchronous updating (Hommes et al., 2005; Diks and van der Weide, 2005)

$$
n_{j, t}=\delta n_{j, t-1}+(1-\delta) \frac{e^{-\beta u_{j, t}}}{z_{t}}
$$

where $z_{t}=\sum_{j=1}^{J} \exp \left(-\beta u_{j, t}\right)$ is a normalization factor. The asynchronous updating parameter $0 \leq \delta \leq 1$ reflects inertia in the choice of the heuristics ${ }^{6}$. In the extreme case $\delta=1$, the initial impacts of the rules never change, no matter what their past performance was. At the other extreme, $\delta=0$, we have the special case of synchronous updating, as in Brock and Hommes (1997), where all agents switch to better strategies in each period. In general, in each period only a fraction $1-\delta$ of the heuristic's weight is updated according to the discrete choice model with asynchronous updating. The parameter $\beta \geq 0$ represents the intensity of choice measuring how sensitive predictor choice is to differences in heuristics' performance. In the extreme case $\beta=0$, the relative weights of heuristics are not updated; at the other extreme $\beta=+\infty$, a fraction $1-\delta$ of agents switch immediately to the best predictor. In the special case where $\delta=0$ and $\beta=\infty$, coined the neoclassical limit in Brock and Hommes (1997), all agents switch immediately to the best forecasting strategy. In the simulations of heterogeneous market equilibrium dynamics below, the parameters will be fixed at $\beta=5, \delta=0.5$ and $\gamma=0$, but the results are fairly robust w.r.t. changes of these parameters. We also check the robustness by studying analytically the neoclassical limit case.

\subsection{Heterogeneous market equilibrium}

Under heterogeneous expectations, we define total supply of loans at date $t$ as

$$
S_{t}\left(r_{t}\right)=\frac{w_{t}}{2} \sum_{j=1}^{J} n_{j, t} \quad \bar{\imath}\left[\lambda_{j, t+1}^{e}\left(r_{t}\right)>\rho\right]=\frac{w_{t}}{2} \sum_{j=1}^{J} n_{j, t} \quad \bar{\imath}\left[p_{j, t+1}^{e} r_{t}>\rho\right],
$$

\footnotetext{
${ }^{6}$ In recent laboratory experiments in various settings, for example in asset pricing forecasting (Anufriev and Hommes, 2012), in positive feedback (asset) and negative feedback (cobweb) markets (Anufriev et al., 2013b) and in a New Keynesian macro framework (Assenza et al., 2013), it has been found that the value of the inertia parameter $\delta=0.8$ or 0.9 is high so that there is a strong tendency to stick to some rule before switching to another rule.
} 


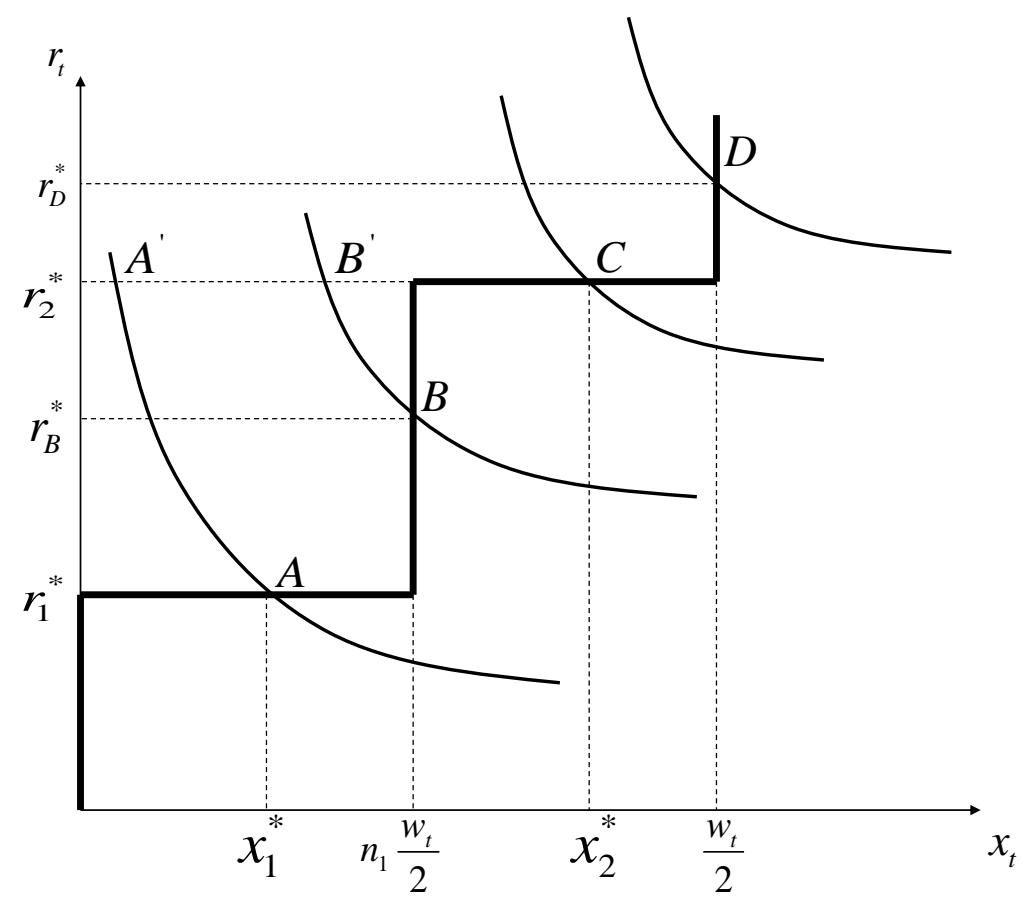

Figure 3: Temporary equilibria in the 2-type case, with four possible loan market equilibrium points $\mathrm{A}, \mathrm{B}, \mathrm{C}$ and $\mathrm{D}$, depending on the time-varying supply and demand curves. The figure illustrates the case $p_{1, t+1}^{e}>p_{2, t+1}^{e}$, that is, type 2 are more pessimistic. The loan supply correspondence is a 2-step function with critical threshold levels at $r^{*}=\rho / p_{1, t+1}^{e}$, where the loan supply switches from 0 to $n_{1 t} w_{t} / 2$, and at $r^{*}=\rho / p_{2, t+1}^{e}$, where the loan supply switches from $n_{1 t} w_{t} / 2$ to $w_{t} / 2$. As the fraction of the pessimistic type 2 increases, the equilibria $\mathrm{B}$ and $\mathrm{A}$ shift to $B^{\prime}$ and $A^{\prime}$.

where $p_{j, t+1}^{e}$ represents expectations of type $j$ about the probability of success and $n_{j, t}$ represents the fraction of agents of type $j$ at time $t$. Here the last equality follows from Eq. (2.17). Temporary equilibrium in the loan market is given by

$$
x\left(r_{t} ; p_{t}\right)=S_{t}\left(r_{t}\right)=\frac{w_{t}}{2} \sum_{j=1}^{J} n_{j, t} \bar{\imath}\left[p_{j, t+1}^{e} r_{t}>\rho\right] .
$$

Figure 3 illustrates market equilibrium in the case of heterogeneous expectations with two types of agents $(J=2)$. Recall that, in the homogeneous case, the loan supply correspondence (2.20) is a step function (see Figure 1), with the loan supply switching from 0 to $w_{t} / 2$ at the threshold $r^{*}=\rho / p_{t+1}^{e}$, whose value is determined by the expected probability of success. In the heterogeneous case with two types of expectations, $p_{1, t+1}^{e}$ and $p_{2, t+1}^{e}$, the loan supply correspondence is a 2-step function. If, for example, $p_{1, t+1}^{e}>$ $p_{2, t+1}^{e}$, i.e. type 2 are more pessimistic, then the threshold levels are $r_{1}^{*}=\rho / p_{1, t+1}^{e}$, where the loan supply switches from 0 to $n_{1 t} w_{t} / 2$, and $r_{2}^{*}=\rho / p_{2, t+1}^{e}$, where the loan supply switches from $n_{1 t} w_{t} / 2$ to $w_{t} / 2$.

Note that (4.6) is a temporary equilibrium relation, with time varying demand function $x\left(r_{t} ; p_{t}\right)$ in $(2.9)$ depending on the success probability $p_{t}$, and time varying supply 
correspondence in (4.5), depending on time varying aggregate savings $w_{t} / 2$, time varying fractions $n_{j, t}$ and individual expectations $p_{j, t+1}^{e}$. Figure 3 illustrates four possible temporary equilibrium points $\mathrm{A}, \mathrm{B}, \mathrm{C}$ and $\mathrm{D}$, depending on the temporary supply and demand curves, in a simple 2-type case. It is important to note that as the fraction of the most pessimistic forecasting rule 2 increases, the vertical threshold at $n_{1, t} w_{t} / 2$ shifts to the left and the equilibrium point (depending on the temporary demand curve) shifts from B to B' or from A to A'. Consequently, an increase of the fraction of the most pessimistic forecasting rule leads to a high contract rate $r^{*}$ and a lower equilibrium loan $x^{*}$ and a correspondingly lower output. Similarly, an increase in the most optimistic forecasting rule leads to a lower equilibrium contract rate and a higher equilibrium output. Stated differently, an increase in the fraction of the most pessimistic (optimistic) forecasting rule amplifies an economic crisis or bust (boom).

\section{A stylized example with six belief types}

Consider the heterogeneous beliefs case with six expectations rules taken from the homogenous benchmarks: rational, naive, average, trend-following, pessimistic and optimistic expectations. In the simulations the exogenous $\mathrm{AR}(1)$ stochastic time series of the probability of success is the same as for the homogeneous benchmarks before, with its minimum realization in the "crisis-period" 31.

Rational agents know the true exogenous probability generating process (3.1) and therefore use the optimal, model consistent $\operatorname{AR}(1)$ forecasting rule to predict the firms' probability of success. Notice that $\mathrm{AR}(1)$ forecasters are not only rational forecasters, but also rational optimizers maximizing utility (2.1) under the budget constraint (2.2$2.3)$, given their forecast of the expected loan return $\lambda_{t+1}^{e}=p_{t+1}^{e} r_{t}$ in (2.17). Since the equilibrium contract rate $r_{t}$ is known before making the forecasts, agents correctly take the behavior of other non-rational agents, who affect this equilibrium contract rate $r_{t}$, into account ${ }^{7}$.

In this section, our analysis focusses on problems caused by excessively pessimistic expectations, to study the occurrence of and recovery from a crisis after a drop of confidence in the economy, but in Section 6 we study the endogenous formation of both economic booms and busts.

Figure 4 illustrates the dynamics of the 6 -type case. The fractions of all types (middle panels) show considerable fluctuations, fluctuating between 0 and 0.3 , with rational and naive expectations dominating (ranging from $0.15-0.3$ ), trend followers somewhere in between (ranging from $0.05-0.25$ ), and average, pessimistic and optimistic expectations wildly fluctuating (between 0 and 0.25 ) at times being the minority types, but never

\footnotetext{
${ }^{7}$ The same is true for other subjective forecasting rules, but $\mathrm{AR}(1)$ forecasters are the only agents who are both rational optimizers and rational forecasters, while other forecasting rules are not rational forecasters as they are not model consistent with the exogenous stochastic probability process. See Sargent (1993) for a discussion of optimization and forecasting as two different aspects of rationality.
} 


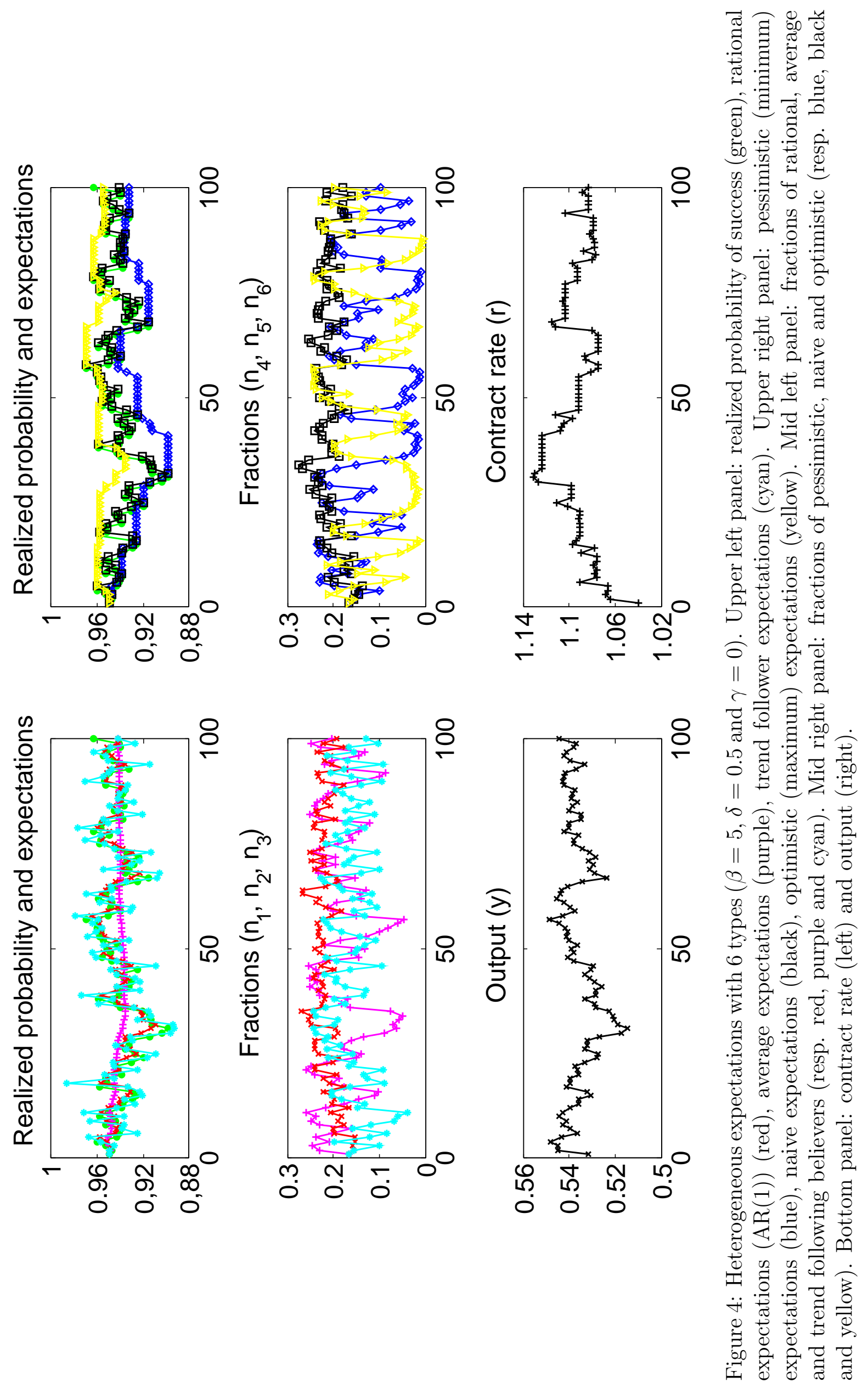


completely driven out of the market.

The contract rate (bottom right panel) gradually increases hitting its peak around periods $30-33$ and remaining persistently high between periods $34-42$. Overall, the contract rate is persistently higher than the long run equilibrium rate $\bar{r}=\rho / \mu=1.063$, due to the presence of pessimistic forecasters, even when their fractions are relatively small. Around the exogenously generated crisis of period 31, the fraction of pessimistic expectations are at a peak, around 0.25, and only decrease gradually thereafter. A relatively small fraction of pessimistic traders thus has a significant impact on aggregate outcomes and contributes to a high equilibrium contract rates for more than 10 periods. The time series of output $g(x)$ is also shown (bottom left panel), with a minimum value at the exogenously generated crisis in period 31 and only slowly recovering in subsequent periods.

Figure 5 compares the 6 -type heterogeneous expectations simulations with the homogeneous rational expectations benchmark. In particular, Figure 5 (top right panel) illustrates that the difference of the contract rates under boundedly rational heterogeneous expectations and homogeneous rational expectations is significantly positive over the entire sample and highly persistent. The heterogeneous expectations bias of the contract rate for loans is $\bar{r}^{H E T}-\bar{r}^{R E} \approx 2.4 \%$. Its peak is substantial, about $6.8 \%$, and occurs in period 39, that is, much later than the worst exogenous shock in the crisis period 31, at times when the rational forecast has already correctly predicted the mean reversion of the probability of success towards its mean, while under heterogeneous expectations the influence of a relatively small fraction of pessimistic agents on aggregate behaviour is still highly significant.

Similarly, the bottom panel of Figure 5 illustrates differences in output under heterogeneous versus homogeneous rational expectations. Under heterogeneous expectations, output is significantly lower than under rational expectations. On average, the output loss $\left(y^{R E}-y^{H e t}\right) / y^{R E}$ due to heterogeneous expectations is about $1.1 \%$, with a peak of more than $3 \%$. As for the peak in the differences in the contract rate, the biggest output loss due to heterogeneous expectations occurs in period 39, much later than the crisis period 31, and it occurs when in fact the exogenous probability of success already has recovered to normal levels, but a drop of confidence due to boundedly rational heterogeneous expectations still affects output at the macro level significantly, even when the fractions of pessimists at the micro level is relatively small.

\section{Why do non-rational strategies survive?}

Why then are the fully rational agents, using the AR(1) model consistent forecasting rule of the exogenous probability of success, not driving out all other forecasting rules, as has been suggested by the traditional rational approach, advocated e.g. by Friedman 

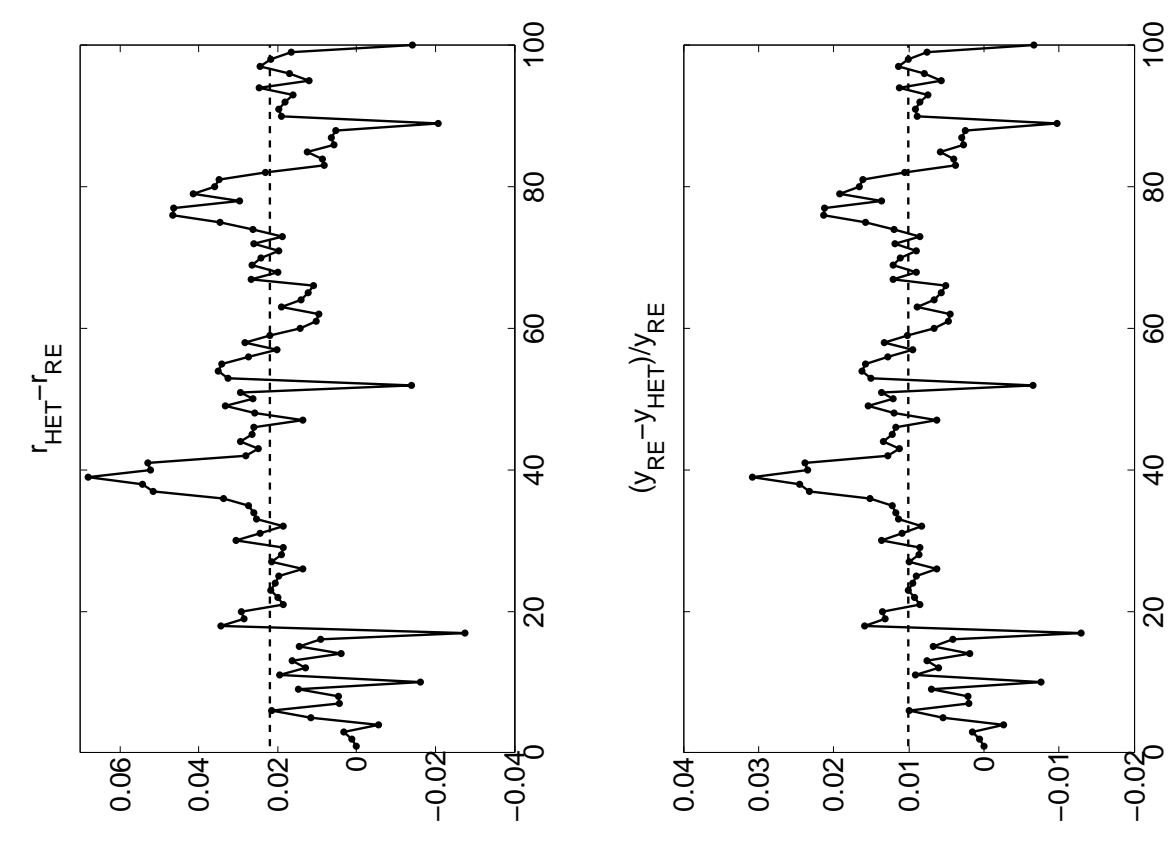

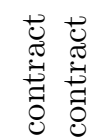

苛.

త్ర

岕:

苍寻.

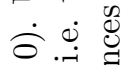

॥

등.

สี

0 苫

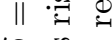

10

$\|$ 氜

S

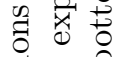

胥

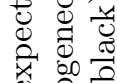

ن

跑

毒

过

0.

范

눈
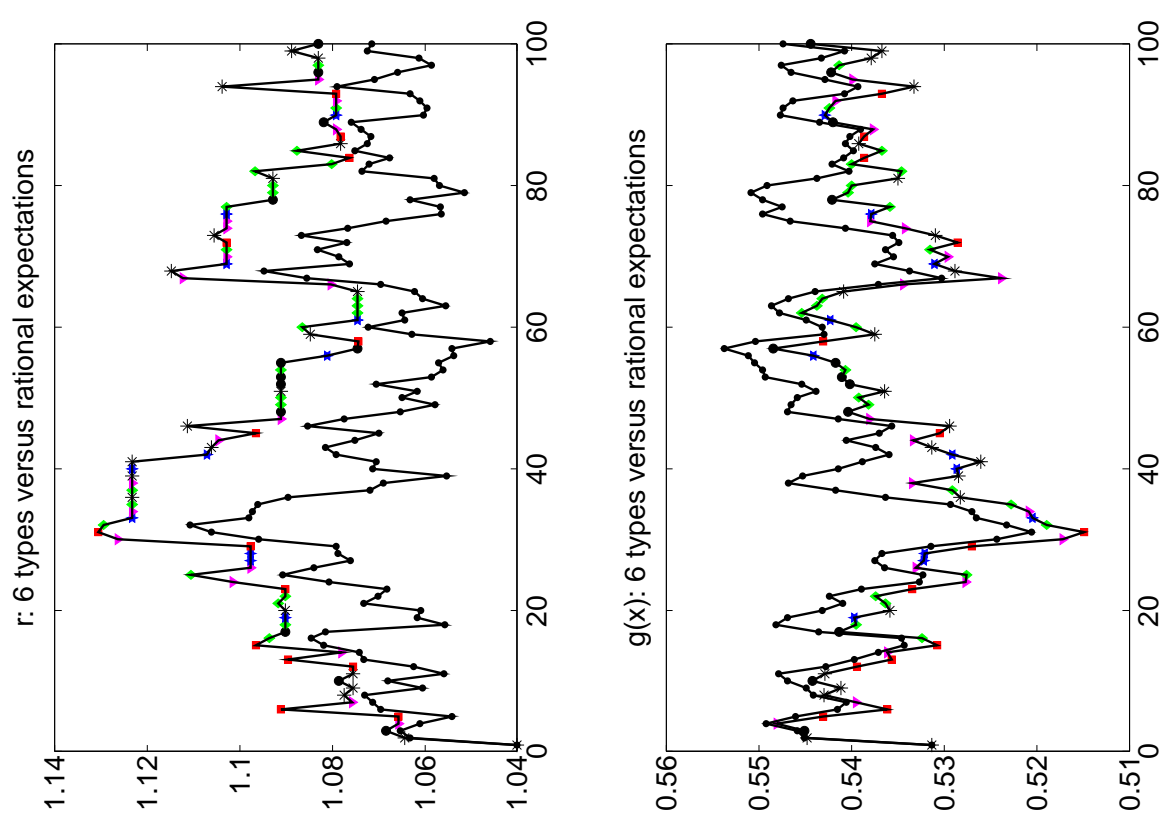

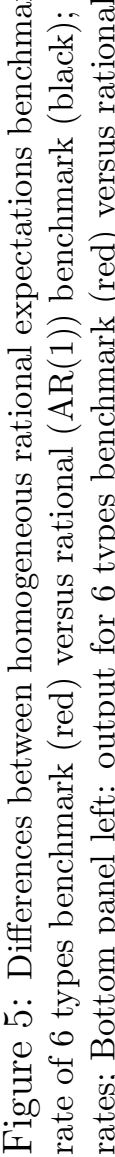


(1953) and Fama $(1970)^{8}$

In order to address this question we first study analytically the case $\delta=0$ (i.e. synchronous updating), $\gamma=0$ (i.e. no memory) and $\beta=\infty$ (immediate switching to the best performing rule). Brock and Hommes (1997) coined this case a "neoclassical limit", with all agents immediately switching to the best performing rule ${ }^{9}$.

Figure 6 compares the 6 -type heterogeneous expectations simulations (with $\beta=\infty$ and $\delta=0$ ) to the homogeneous rational expectations benchmark. The reader should compare these to Figure 5 (with $\beta=5$ and $\delta=0.5$ ). The results are very similar, with only some minor differences.

Figure 6 (top panels) illustrate that the difference of the contract rates in the heterogeneous expectations case with $\beta=\infty$ is still significantly positive over the entire sample, only with occasional drops below zero, and highly persistent. Hence, also in the case when all agents switch immediately to the best performing rule, we observe a heterogeneous expectations bias of the contract rate for loans. The average heterogeneous expectations bias is $\bar{r}^{H E T}-\bar{r}^{R E} \approx 1.8 \%$, with its peak around $6.8 \%$ in period 39 , as before

Similarly, the bottom panels of Figure 6 illustrates differences in output under heterogeneous expectations with $\beta=\infty$ versus homogeneous rational expectations. Again heterogeneous expectations, output is significantly lower than under rational expectations, with an average output loss $\left(y^{R E}-y^{H e t}\right) / y^{R E}$ of about $0.8 \%$, with a peak of more than $3 \%$ in period 39 .

Our analysis of the limiting case $\beta=\infty$ shows that the rational expectations strategy is not always the best strategy and therefore, based upon their relative success, agents may switch temporarily to alternative expectations rules. The colored dots, squares, triangles and stars along the time series in Figures 5 and 6 both indicate the best performing strategy over time. It is clear that there is no single dominating strategy, but rather the optimal strategy fluctuates. For example, the pessimistic rule is the best in periods 29 , just before the crisis, and in period 31 at the peak of the crisis. In period 30 , just before the peak of the crisis, the trend-following rule dominates, amplifying the crisis. In periods 32 and 35, the rational expectations rule is the best, at a time when the probability of success is still rather low.

Based on the analytical results for the "neoclassical limiting case", we can discuss the main driving forces behind the 6-belief-types simulation results with boundedly rational heterogeneous expectations selection $(\beta=5)$ and asynchronous updating $(\delta=0.5)$. There are four key elements of why non-rational forecasting rules survive in our economy with performance based strategy selection: (1) bounded rationality, (2) finite memory

\footnotetext{
${ }^{8}$ We stress once more that $\mathrm{AR}(1)$ forecasters are fully rational in our framework, as they are both rational forecasters and utility maximizers taking the behavior of other non-rational agents into account through their knowledge of the equilibrium contract rate $r_{t}$; see the discussion in Section 5 .

${ }^{9}$ We stress that the "simulations" for the neoclassical limit $\beta=\infty$ should be viewed as analytical results since, given the random realizations of the exogenous probability time series, a comparison of the forecasting errors of the 6 strategies exactly determines the optimal rule at each period in time.
} 

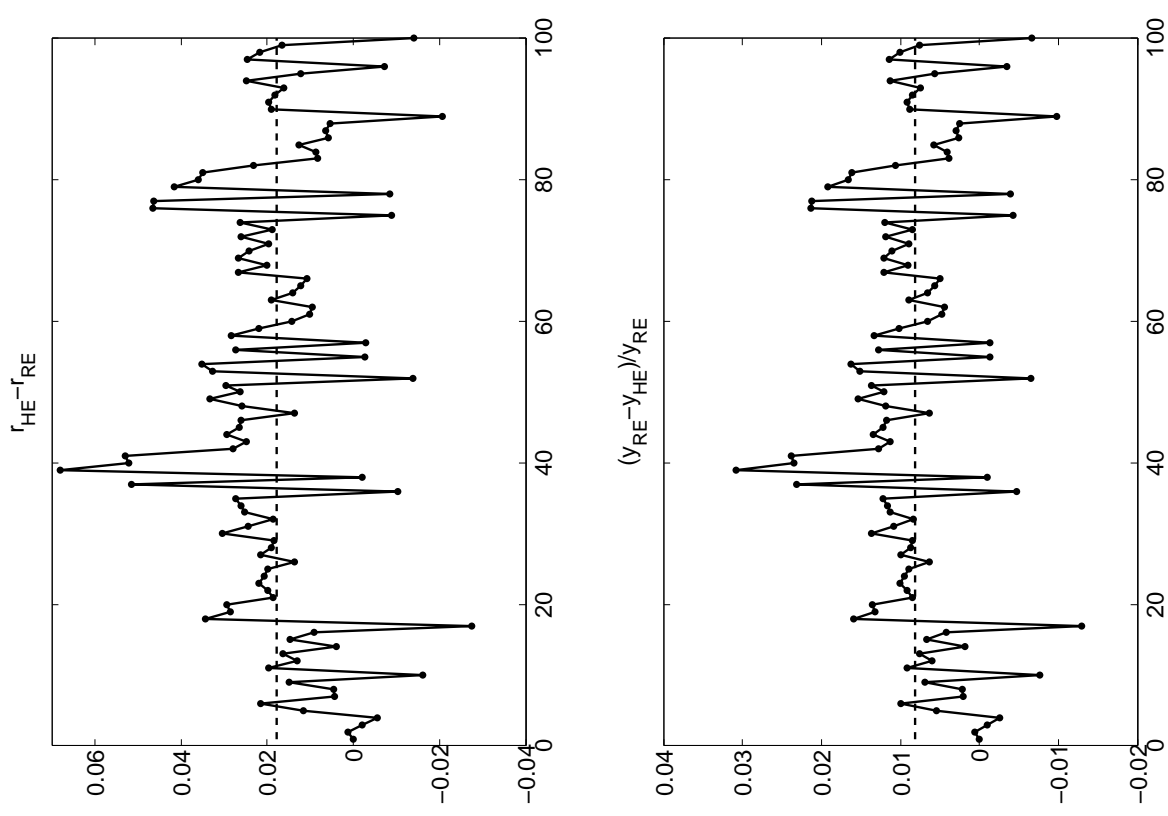

实.

$\circ \dot{0}$

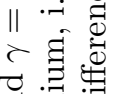

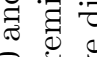

○ $\vec{a}$.

$\infty$ 雪

8 艺

11.0

范

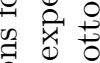

요요

홍

잉

o 원

号垫

త્વ

히잉

.

흉

范
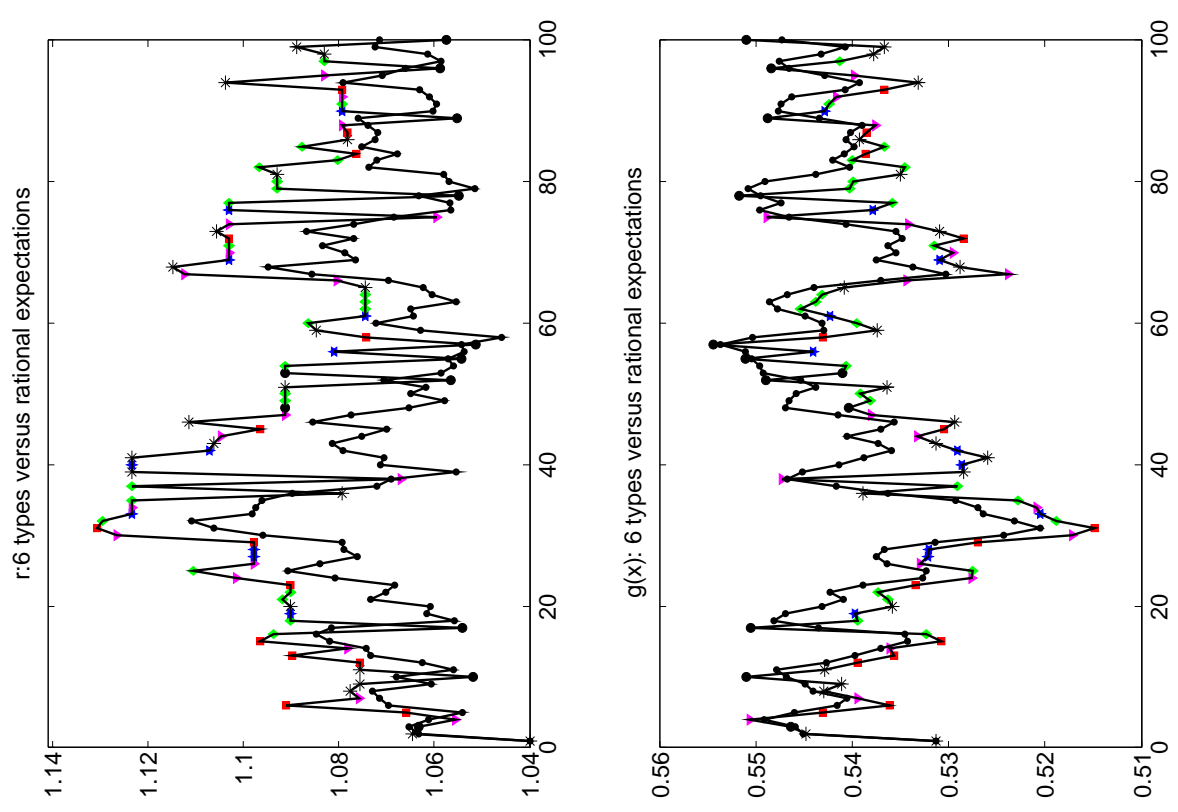

胥

$\frac{\pi}{2}$

0 의

ปี

苍导

过

悉

శ్

넌

雨

ठ․ㄹ

800

ఏ్ష

己ृ

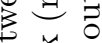

远

웡 잉

ठㄹ

屯ี

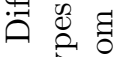

$\ddot{0}$

00 ค

$=$

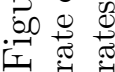


and more weight to recent performance, (3) asymmetry giving higher weight to forecast errors in "bad times", and (4) inertia due to asynchronous strategy updating.

1. Agents choose between heterogeneous forecasting rules based upon recent forecasting performance. Their choice is boundedly rational in the sense that their intensity of choice to switch strategies is finite, i.e. $\beta<\infty$, implying that some agents will not switch to the best strategy, but choose an alternative rule. Hence, for $\beta<\infty$, each rule attracts some followers. When $\beta \approx 0$, the distribution of the population over the forecasting rules is flat, with fractions approximately equal. For $\beta \approx \infty$ the distribution over rules is peaked, with most agents choosing the best strategy.

2. In general, the performance measure is a weighted average of past (relative) forecasting errors, as in (4.2). In the (special) case when the contract rate $r_{t}$ would be constant over time and memory would be infinite (i.e. $\gamma=1$ ), the performance measure is, up to a scaling factor, equivalent to the mean squated error (MSE). Therefore, in the special case of constant contract rate, infinite memory $\gamma=1$ and infinite intensity of choice $\beta=+\infty$, in the long run the rational $\operatorname{AR}(1)$ forecast would drive out all other forecasting rules. Hence, the rational benchmark is nested within our framework as a special case. In the more realistic case when memory is finite, i.e. $0 \leq \gamma<1$, agents give more weight to recent observations. When more weight is given to recent observations, rational expectations can be suboptimal. Indeed, as we have seen for the "neoclassical limiting case", at times other rules perform better than the rational $\mathrm{AR}(1)$ rule. In particular, in "bad" times the pessimistic rule performs relatively well, while in "good" times the optimistic rule performs relatively well.

There is empirical evidence that recent performance is important for strategy selection. For example, evidence from empirical finance suggests that the flow in and out of mutual funds is strongly driven by the recent past performance of these funds (e.g. Sirri and Tufano, 1998, Karceski, 2002). Similarly, using data, Vanguard, Benartzi and Thaler (2007) have shown for retirement savings decisions that equity allocation of new participants rose from 58\% in 1992 to $74 \%$ in 2000, following a strong rise in stock prices in the late 1990s, but dropped, back to $54 \%$ in 2002, following a strong fall in stock prices. In recent laboratory experiments with human subjects, Anufriev et al. (2012) show that individuals switch to alternative strategies which performed better in the recent past, even when such performance was driven by an exogenous random sequence and individuals had enough information about which strategy was optimal on average.

3. In our economy, agents are forecasting the expected return on the risky asset, $\lambda_{j, t}^{e}=p_{j, t}^{e} r_{t-1}$, depending on their forecast $p_{j, t}^{e}$ of the probability of success. The squared prediction error then becomes $r_{t-1}^{2}\left(p_{t}-p_{j, t}^{e}\right)^{2}$ and is proportional to the 
squared prediction error of the probability of success, with a time varying weight $r_{t-1}$. This introduces an asymmetry in the forecasting performance: in times when the contract rate is high (low), more (less) weight is given to recent forecasting errors. High contract rates arise in "bad times", when the exogenous probability of success is low and pessimistic forecasting rules perform relatively well. Due to this asymmetry, in "bad times" pessimistic expectations will kick in more easily than optimistic expectations will in "good" times.

4. Our expectations selection framework (4.2-4.4) is an extension of the model with synchronous updating of Brock and Hommes (1997), allowing for asynchronous updating (Hommes et al., 2005b; Diks and van der Weide, 2005). The introduces inertia in strategy switching, through the parameter $0<\delta<1$, representing the fraction of agents that will stick to their previous strategy, while in a given period only a fraction $1-\delta$ switches strategy based on relative performance. This inertia in strategy switching due to asynchronous updating is in some sense similar to rational inattention (Sims, 1998, 2003). Anufriev and Hommes (2012) fitted the heterogeneous expectations switching model with asynchronous updating to experimental data and found relative large values around $\delta=0.8$. Consequently, once non-rational expectations rule gain some weight, e.g. in "bad" times, when a fraction of agents becomes pessimistic, asynchronous strategy updating implies that they only disappear gradually afterwards. As a consequence, a relatively small fraction of pessimistic agents may increase the persistence of crisis considerable leading to a very slow recovery of the economy.

These four plausible and empirically relevant elements of strategy switching cause non-rational rules to survive in a heterogeneous population. In particular, in bad times they cause (at least) a small fraction of agents to have pessimistic expectations. But even a relatively small fraction of pessimistic believers has a significant effect upon aggregate behaviour and causes crises to be deeper and more persistent. Similarly, in good times (at least) a small fraction will adopt an optimistic rule amplifying and lengthening the boom of the economy.

\section{Endogenous probability of success}

So far, the loan probability of success has been an exogenous stochastic AR(1) process. In this section we endogenize the probability of success of the economy, making it dependent on the state of the economy, to study the emergence of boom and bust cycles in an economy with endogenous (positive) expectations feedback. It is natural to assume that the probability for a firm to be successful is positively correlated with the state of the economy as measured by output. The simplest natural extension to an endogenous 
success probability is given by

$$
p_{t+1}=\mu+a\left(p_{t}-\mu\right)+b\left(y_{t}-\bar{y}\right)+\epsilon_{t},
$$

where the first part represents the exogenous $\mathrm{AR}(1)$ process (3.1), with the same long run mean $\mu=0.95$, the same first order autocorrelation coefficient $a=0.8$ and the same realizations of the IID noise $\epsilon_{t}$. The second part models an endogenous linear dependence of the probability of success upon the output gap, measured by the difference of output from its moving average $\bar{y}=\frac{1}{T} \sum_{i=1}^{T} y_{t-i}$. This linear endogenous dependence may be viewed as a first order approximation of a more general nonlinear endogenous dependence of the success probability on the output gap, with the parameter $b \geq 0$ measuring its strength (in the simulations we set $b=0.8$ ). The endogenous probability (6.1) thus represents the simplest, linear representation of positive feedback from the output gap to the probability of success or, equivalently, negative feedback from the output gap to the default probability ${ }^{10}$.

Figure 7 shows the simulated time series of the endogenous realized probability, the six forecasts, the fractions of all six types, output and the contract rate, for the 6-type model with endogenous success probability. An immediate observation is the large swings in the contract rate and output driven by large fluctuations in the endogenous default probability. Positive feedback from output into the firms' success probability amplifies the boom and bust cycles in the economy. The contract rate exhibits persistently high values (around 1.15) around the (exogenous) "crisis period" 31 and even higher values $(>1.2)$ between periods 70-80. Output drops below 0.5 in period 31 and below 0.47 around period 75 . The fractions of the six strategies show how each of the rules reenforces different phases of the boom and bust cycles. Optimistic expectations kick in at good times and lead to persistent phases of high success probability, low contract rates and high output. In contrast, the fraction of pessimistic expectations increases in bad times, leading to persistently low success probability, high contract rates and low output. Optimists and pessimists thus amplify booms and busts. The rational expectations rule here is given by

$$
p_{t+1}=\mu+a\left(p_{t}-\mu\right)+b\left(y_{t}-\bar{y}\right)
$$

using the correct model consistent forecast and only making a small error that equals the noise term $\epsilon_{t}$. Hence, rational agents perfectly recognize both the exogenous part of the probability process and the endogenous dependence on output. The RE rule does well most of the time, but naive and trend-following expectations at times are equally good and occasionally, due to the noise, even slightly better and that may cause even higher booms or lower busts. The average expectations rule performs poorly and this

\footnotetext{
${ }^{10}$ Bruneau et al. (2011) provide empirical support for such a negative relationship, showing a negative correlation between the number of bankruptcies and the output gap for France.
} 
总

:

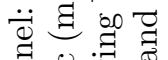

苨苛

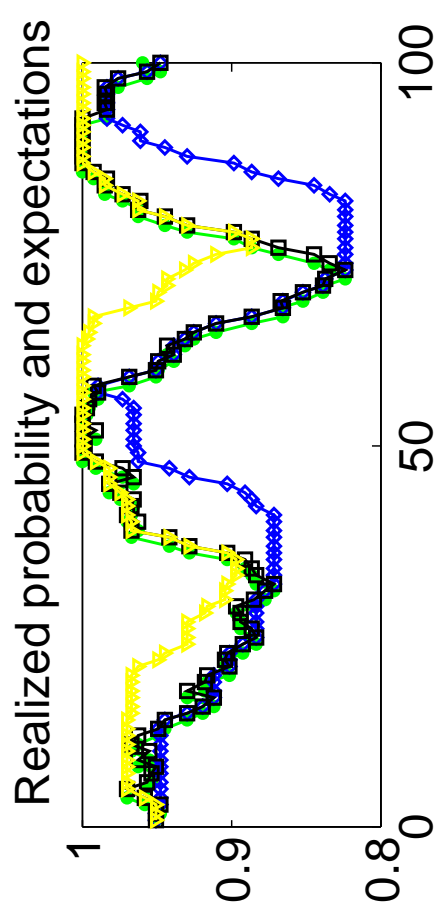

옹
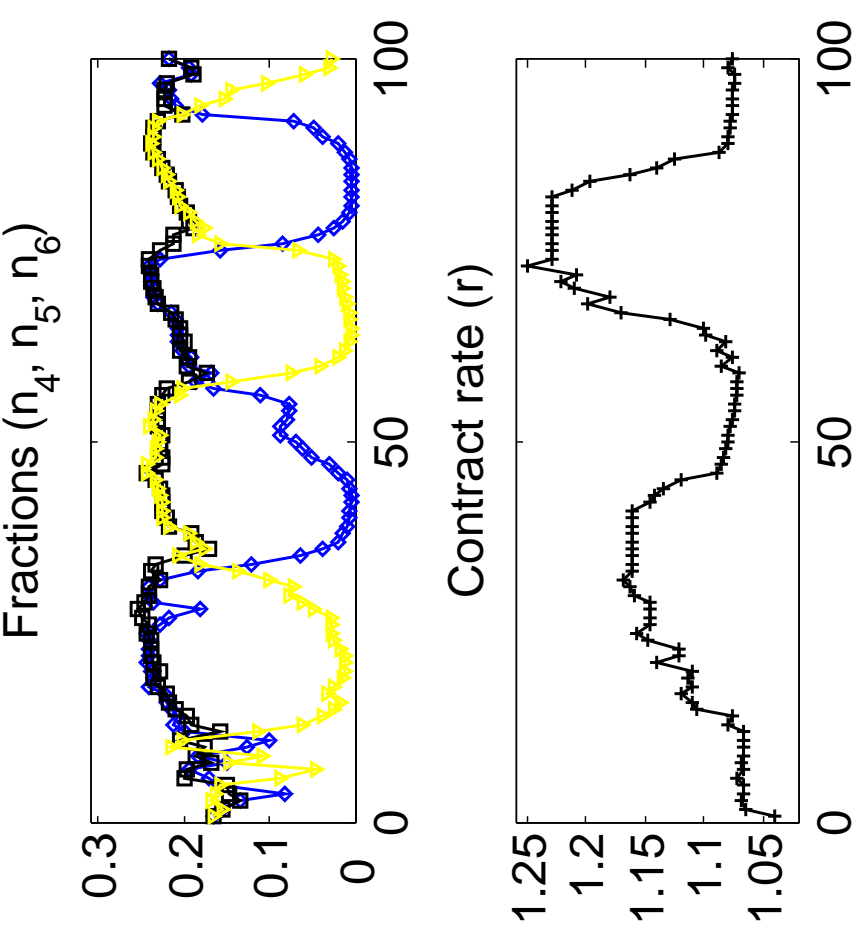

屯.

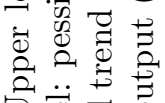

5 च

oิ

II 50

F

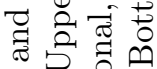

语完焉

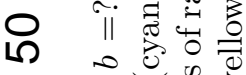

0 朋

$\|$.

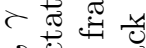

10.

110.0

$\infty$ 过

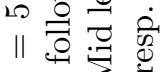

07

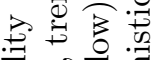

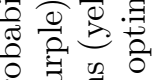
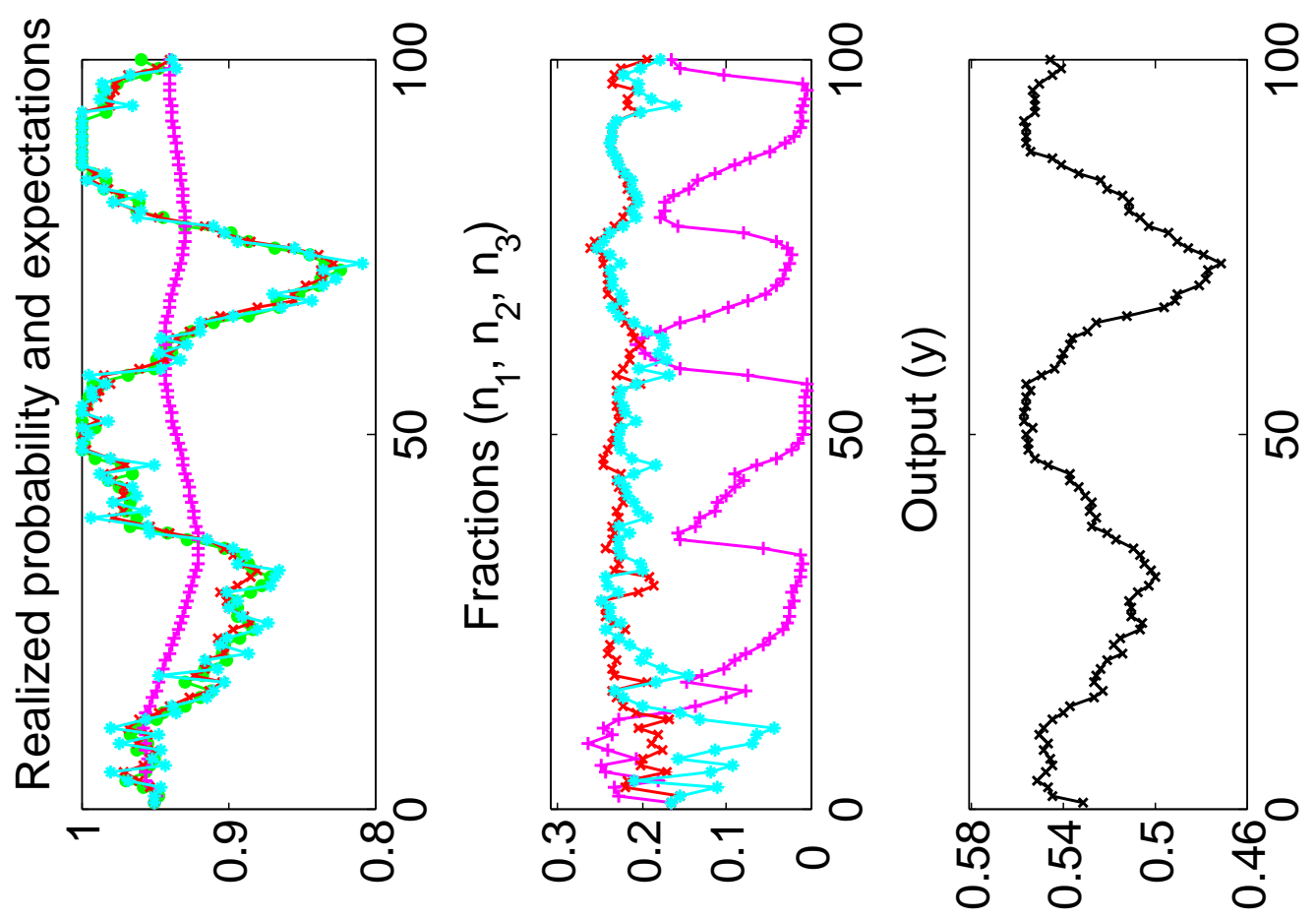

苨.

告

का

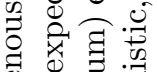

$\infty$ \&. $₫$

需

च

कै छิ

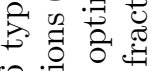

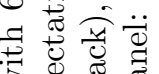

उ.

预

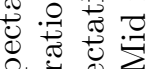

ชิ

造.

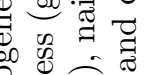

$\begin{array}{lll}0 & 0 \\ 0 & 0 & 0 \\ 0 & 0 & 0 \\ 0 & 0 & 0 \\ 0 & 0 & 0\end{array}$

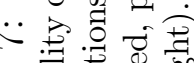

o: : :

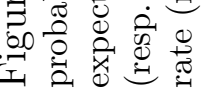



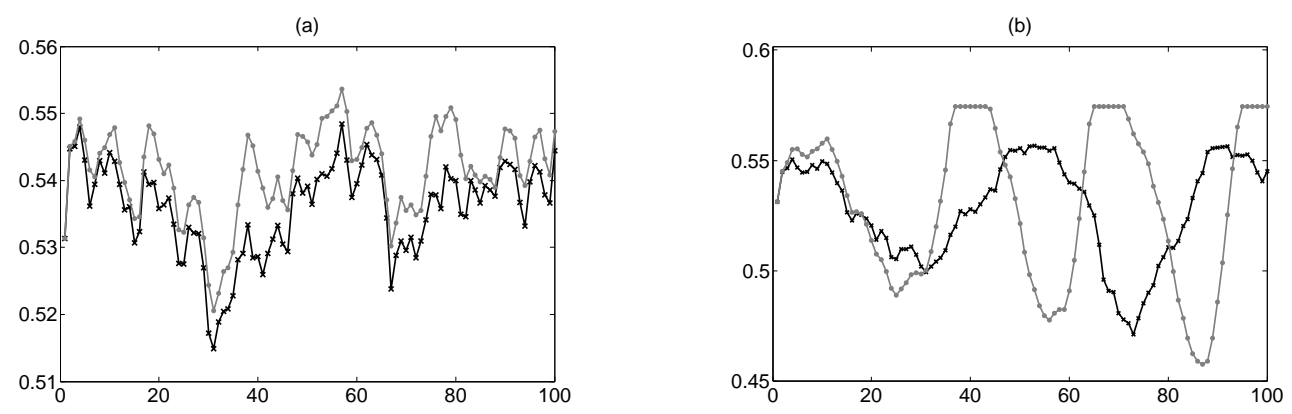

Figure 8: Panel (a): Output (exogenous probability). Grey: rational expectations benchmark; black: 6 types ; panel (b): Output (endogenous probability). Grey: rational expectations benchmark; black: 6 types.

type of averaging rule has limited effect on the emerging aggregate behavior.

Figure 8 compares the output series for RE and the 6-type heterogeneous expectations model for the exogenous $\mathrm{AR}(1)$ probability series (3.1) as well as the endogenous probability series (6.1). In the case of an exogenous probability (left panel), the 6-type heterogeneous expectations model leads to deeper crises and slower recovery, as discussed in Section 5 (cf. Figure 5). In the case of an endogenous probability (right panel) both the RE benchmark and the 6-type model lead to even larger boom and bust cycles. The RE rule correctly anticipates the positive feedback from output to the success probability and as a consequence leads to self-fulfilling amplification of boom and bust cycles. The 6-type model tracks these large boom and bust cycles, but with increasingly long delays due to slower mean reversion. As we have seen already in Figure 7, the boundedly rational heterogeneous expectations of the endogenous success probability are almost self-fulfilling, leading to amplified boom and bust cycles, but much slower and with much weaker mean reversion than in a perfectly rational world. This may have important consequences for the timing of monetary and fiscal policy. The timing of booms and busts is different in a boundedly rational heterogeneous world compared to a perfect RE world and policy should take these differences into account for more effective policy under realistic assumptions.

Figure 9 compares the homogeneous RE benchmark and our heterogeneous neoclassical limit case $(\beta=\infty, \delta=\gamma=0)$, showing the realized probability (left panel) and the output series (right panel) in both cases. The neoclassical limit case closely tracks the RE benchmark, which is nested as a special case. Interestingly, the 6-type heterogenous expectations occasionally leads to even larger amplitude of the boom and bust cycles, when at the peak or at the bottom the trend-following rule performs better than the RE rule, and to slower recovery due to slower mean reversion. These (analytical) results for the neoclassical limit case stress the importance of the timing of policy under boundedly rational heterogeneous expectations. 

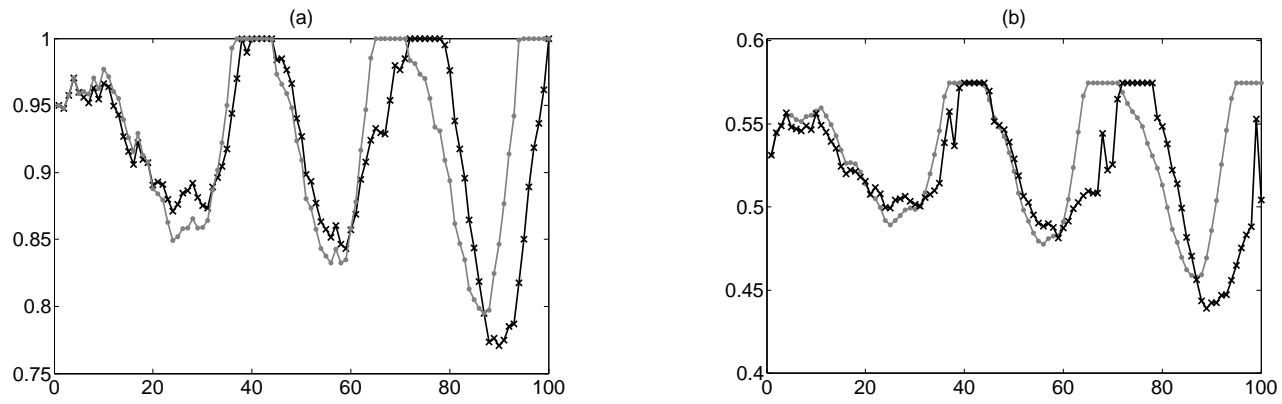

Figure 9: Panel (a): exogenous probability. Grey: rational expectations benchmark; black: heterogeneous neoclassical limit case ; panel (b): output. Grey: rational expectations benchmark; black: heterogeneous neoclassical limit case.

We conclude that, in the case of an endogenous probability of success the economy exhibits expectations driven macroeconomic fluctuations. A rational expectations rule on average correctly predicts exogenous mean reversion and perfectly predicts the positive feedback from output gap on the success probability. Nevertheless, non-rational forecasting rules at times may perform better than the RE forecast. Boundedly rational heterogeneous expectations rules thus survive competition. Due to the presence of trend-followers, under heterogeneous expectations booms turn out to be higher and busts deeper due to overreaction. Moreover, the recovery from crises is slower, due to the presence of pessimistic expectations causing much slower mean reversion.

\section{Conclusion}

This paper is an attempt to build a model of "animal spirits" and "confidence", as advocated in Akerlof and Shiller (2009). Our building block is the heterogeneous expectations switching model of Brock and Hommes (1997). We have studied an equilibrium model for loans and compared the case of expectations heterogeneity to the standard case of homogeneous rational expectations. Heterogeneous expectations are disciplined by evolutionary selection or reinforcement learning based upon recent forecasting performance. Survey data on expectations, laboratory forecasting experiments and time series data lend empirical support to such a heterogeneous expectations hypothesis. Costless rational expectations, whose forecast uses the correct model consistent specification of the stochastic probability of success, are unable to drive out simple forecasting heuristics such as naive expectations, trend following rules and pessimistic or optimistic expectations. In particular, a small fraction of pessimistic expectations survives, and even a small fraction of pessimistic believers has a large impact on aggregate macro behaviour. Even in the presence of costless fully rational expectations a small fraction of pessimistic or optimistic agents at the micro level may have a relatively large aggregate effect at 
the macro level and cause economic booms and busts to be higher and deeper and recovery from crisis to be much slower. These booms and busts are amplified by almost self-fulfilling expectations due to the positive feedback in our macroeconomic system ${ }^{11}$. The different timing of boom and bust cycles under heterogeneous expectations may have important consequences for the timing of monetary and fiscal policy.

In a recent survey, Brunnermeier et al. (2012) focus on financial frictions as the key mechanism causing persistence, amplification and instability at the macro economic level. While financial frictions may play an important role, our results show that persistence, amplifications and instability arise even without any financial frictions in a simple stylized equilibrium model of boundedly rational agents with heterogeneous expectations. If bounded rationality, animal spirits and expectations heterogeneity are indeed important drivers of macro economic instability amplifying economic crises and slowing down recovery, policy should not only focus on financial frictions but also on managing heterogeneous expectations, trend following behaviour and over pessimistic beliefs about the economy. Moreover, economics profession should pay more attention to animal spirits and expectational heterogeneity and their potentially destabilizing role and negative welfare effects in order to prevent economic losses ${ }^{12}$.

Off course our model is very stylized, but the same heterogeneous expectations framework can be applied to richer and more advanced models, e.g. New Keynesian macro models (e.g. DeGrauwe, 2011; Anufriev et al., 2013a), including models with infinite horizon (Branch and McGough, 2009; Massaro, 2013). Future work should investigate theoretically and empirically the size and persistence of heterogeneity, differences in real variables, such as wages and output, and the implications for the timing of monetary and fiscal policy.

\section{References}

[1] Adam K. (2007): "Experimental Evidence on the Persistence of Output and Inflation". The Economic Journal, 117(520), 603-636.

\footnotetext{
${ }^{11}$ This is consistent with laboratory experiments, e.g. Heemeijer et al. (2009), Assenza et al. (2012) and Bao et al. (2012), where in positive feedback systems subjects coordinate expectations on almost self-fulfilling forecasting rules, such as trend-following or anchor and adjustment rules, thus amplifying market fluctuations.

${ }^{12}$ For example, Brock et al. (2009) discuss the role of financial innovation in generating financial instability. In the traditional financial economics view, under full rationality financial innovation is usually considered to be stabilizing and welfare improving. In contrast, in a simple stylized model with boundedly rational heterogeneous investors Brock et al. (2009) show that financial innovation may destabilize price fluctuations and decrease average welfare. The main reason is that, in the presence of more financial hedging instruments, investors take bigger positions (leverage) amplifying wins or losses of boundedly rational agents, thus destabilizing the market. Policy implications concerning regulating financial innovation may thus be completely opposite whether one adopts a homogeneous rational or a boundedly rational heterogeneous expectations market view.
} 
[2] Akerlof G.A., and R.J. Shiller (2009): "How Human Psychology Drives the Economy, and Why It Matters for Global Capitalism". Princeton University Press.

[3] Alfarano S., T. Lux, and W. Wagner, (2005): "Estimation of agent-based models: The case of an asymmetric herding model". Computational Economics, 26, 19-49.

[4] Allen H. and M.P. Taylor (1990): "Charts, noise and fundamentals in the London foreign exchange market". The Economic Journal 100(400), 49-59.

[5] Amilon H., (2008): "Estimation of an adaptive stock market model with heterogeneous agents. Journal of Empirical Finance 15, 342-362.

[6] Anufriev M., T. Assenza, C.H. Hommes, and D. Massaro (2013a): "Interest Rate Rules and Macroeconomic Stability under Heterogeneous Expectations". Macroeconomic Dynamics, 17, 1574-1604.

[7] Anufriev, M., Hommes, C.H. and Philipse, R., (2013b): "Evolutionary Selection of Expectations in Positive and Negative Feedback Markets". Journal of Evolutionary Economics, 23, 663-688.

[8] Anufriev, M., Bao, T. and Tuinstra, J. (2012): "Switching Behavior in the Lab: Estimation of the Intensity of Choice". CeNDEF working paper, University of Amsterdam.

[9] Anufriev, M., and C.H. Hommes (2012): "Evolutionary Selection of Individual Expectations and Aggregate Outcomes in Asset Pricing Experiments". American Economic Journal: Micro 4(4), 35-64.

[10] Assenza, T., and M. Berardi (2009): "Learning in a Credit Economy". Journal of Economic Dynamics and Control, 33(5), 1159-1169.

[11] Assenza, T., P. Heemeijer, C. Hommes, and D. Massaro (2013): "Individual Expectations and Aggregate Macro Behavior". TI 2013-016/II, Tinbergen Institute Discussion Paper.

[12] Bao, T., Hommes, C.H., Sonnemans, J. and Tuinstra, J. (2012): "Individual expectations, limited rationality and aggregate outcomes". Journal of Economic Dynamics and Control, 36, 1101-1120.

[13] Benartzi, S. and Thaler, R.H. (2007): "Heuristics and biases in retirement savings behavior". Journal of Economic Perspectives 21, 81-104.

[14] Benhabib J., G. W. Evans and S. Honkapohja (2008): "Liquidity Traps and Expectation Dynamics: Fiscal Stimulus or Fiscal Austerity?". NBER Working Paper No. 18114 
[15] Berardi, M. (2007): "Heterogeneity and Misspecifications in Learning". Journal of Money, Credit and Banking, 31, 3203-3227.

[16] Boswijk, H.P., C.H. Hommes, and S. Manzan (2007): "Behavioral heterogeneity in stock prices". Journal of Economic Dynamics and Control, 31 , 1938-1970.

[17] Branch, W. (2004): "The Theory of Rationally Heterogeneous Expectations: Evidence from Survey Data on Inflation Expectations". The Economic Journal, 114(497), 592-621.

[18] Branch, W.A. (2007): "Sticky information and model uncertainty in survey data on inflation expectations". Journal of Economic Dynamics and Control 31, 245-276.

[19] Branch, W., and G. Evans (2006): "Intrinsic Heterogeneity in Expectation Formation". Journal of Economic Theory, 127, 264-295.

[20] Branch, W., and B. McGough (2009): "Monetary Policy in a New Keynesian Model with Heterogeneous Expectations". Journal of Economic Dynamics and Control, 33, $1036-1051$.

[21] Brazier, A., R. Harrison, M. King, and T. Yates (2008): "The Danger of Inflating Expectations of Macroeconomic Stability: Heuristic Switching in an Overlapping Generations Monetary Model". International Journal of Central Banking, 4(2), 219 254.

[22] Brock, W., and P. de Fontnouvelle (2000): "Expectational Diversity in Monetary Economies". Journal of Economic Dynamics and Control, 24(5-7), 725-759.

[23] Brock, W. A., and C. H. Hommes (1997): "A Rational Route to Randomness". Econometrica, 65(5), 1059-1095.

[24] Brock, W.A., and Hommes, C.H. (1998): "Heterogeneous Beliefs and Routes to Chaos in a Simple Asset Pricing Model". Journal of Economic Dynamics and Control, $22,1235-74$.

[25] Brock, W.A., Hommes, C.H. and Wagener, F.O.O., (2009): "More hedging instruments may destabilize markets". Journal of Economic Dynamics and Control 33, 1912-1928.

[26] Brock, W.A., and C. Manski (2008): “Competitive Lending with Partial Knowledge of Loan Repayment". NBER Working paper \#14378.

[27] Brock, W.A., and C. Manski (2011): “Competitive Lending with Partial Knowledge of Loan Repayment". Journal of Money, Credit and Banking, 43(2-3), 441-459.

[28] Bruneau, C., de Brandt, W. and El Amri, W. (2011), "Macroeconomic fluctuations and corporate financial fragility". Working Paper 226, Banque de France. 
[29] Brunnermeier, M.K., Eisenbach, T.M. and Sannikov, Y., (2012): Macroeconomics with financial frictions: a survey. Princeton University.

[30] Colander, D., R.P.F. Holt, and B.J. Rosser (eds.) (2004): "The Changing Face of Economics. Conversations with Cutting Edge Economists". The University of Michigan Press, Ann Arbor.

[31] Colander, D., P. Howitt, A. Kirman, A. Leijonhufvud, and P. Mehrling (2008): "Beyond DSGE Models: Toward an Empirically Based Macroeconomics". American Economic Review, 98(2), 236-240.

[32] Cornea, A.,C.H. Hommes, and D. Massaro (2013) "Behavioral Heterogeneity in U.S. Inflation Dynamics". TI 2013-015/II Tinbergen Institute Discussion Paper.

[33] De Grauwe, P. (2011): "Animal Spirits and Monetary Policy". Economic Theory, $47(2-3), 423-457$.

[34] Diks, C.G.H. and vanderWeide, R., (2005), "Herding, a-synchronous updating and heterogeneity in memory in a CBS". Journal of Economic Dynamics and Control 29, $741-763$.

[35] Duffy, J. (2008): "Macroeconomics: A Survey of Laboratory Research". University of Pittsburgh Working papers \#334.

[36] Dwyer, G.P., Williams, A.W., Battalio, R.C. and Mason, T.I., (1993): "Tests of Rational Expectations in a Stark Setting". The Economic Journal 103, 586-601.

[37] Ellen, ter S. and Zwinkels, R.C.J. (2010): "Oil price dynamics: a behavioral finance approach with heterogeneous agents". Energy Economics 32(6), 1427-1434.

[38] Evans, G., and S. Honkapohja (2003): "Expectations and the Stability Problem for Optimal Monetary Policies". Review of Economic Studies 70, 807-824.

[39] Evans, G., and S. Honkapohja (2006): "Monetary Policy, Expectations and Commitment". The Scandinavian Journal of Economics 108, 15-38.

[40] Evans, G. W., and S. Honkapohja (2001): "Learning and Expectations in Macroeconomics". Princeton University Press.

[41] Evans, G. W., E. Guse and S. Honkapohja (2008): "Liquidity traps, learning and stagnation". European Economic Review 52(8), 1438-1463.

[42] Fama, E.F., (1970): "Efficient capital markets: a review of theory and empirical work". Journal of Finance 25, 383-423. 
[43] Frankel, J.A. and Froot, K.A., (1990): "The Rationality of the Foreign Exchange Rate. Chartists, Fundamentalists and Trading in the Foreign Exchange Market", American Economic Review Papers and Proceedings 80(2), 181-185.

[44] Friedman, M., (1953) The case of flexible exchange rates, In: Essays in positive economics, University of Chicago Press.

[45] Gilli, M. and Winker, P. (2003): "A global optimization heuristic for estimating agent based models". Computational Statistics \& Data Analysis 42, 299-312.

[46] Heemeijer, P., Hommes, C.H., Sonnemans, J., Tuinstra,J., (2009): "Price stability and volatility in markets with positive and negative expectations feedback". Journal of Economic Dynamics \& Control 33, 1052-1072.

[47] Hey, J. D. (1994): "Expectations Formation: Rational or Adaptive or ...?". Journal of Economic Behavior and Organization, 25, 329-349.

[48] Hommes, C.H. (2011): "The Heterogeneous Expectations Hypothesis: Some Evidence from The Lab". Journal of Economic Dynamics and Control 35(1), 1-24.

[49] Hommes, C. (2006): "Heterogeneous Agent Models in Economics and Finance", in Handbook of Computational Economics Vol. 2: Agent-Based Computational Economics, K. Judd, and L. Tesfatsion (eds.). Elsevier/North-Holland (Handbooks in Economics Series).

[50] Hommes, C., J. Sonnemans, J. Tuinstra, and H. van de Velden (2005a): "Coordination of Expectations in Asset Pricing Experiments". Review of Financial Studies, 18(3), 955-980.

[51] Hommes, C.H., Huang, H. and Wang, D. (2005b): "A robust rational route to randomness in a simple asset pricing model". Journal of Economic Dynamics and Control 29, 1043-1072.

[52] Jong, de E., Verschoor, W.F.C. and Zwinkels, R.C.J. (2009): "Behavioural heterogeneity and shift-contagion: Evidence from the Asian crisis". Journal of Economic Dynamics and Control 33, 1929-1944.

[53] Karceski, J. (2002), "Returns-chasing behavior, mutual funds, and betas death". Journal of Financial and Quantitative Analysis 37, 559-594.

[54] Lines, M., and F. Westerhoff (2010): "Inflation Expectations and Macroeconomic Dynamics: The Case of Rational versus Extrapolative Expectations". Journal of Economic Dynamics and Control 34, 246-257.

[55] Lof, M. (2012), "Heterogeneity in stock prices: A STAR model with multivariate transition function", Journal of Economic Dynamics and Control, forthcoming. 
[56] Mamatzakis, E. (2013), "Are there any animal spirits behind the scenes of the Euro area sovereign debt crisis?". Hellenic Observatory Papers on Greece and Southeast Europe, GreeSE Paper No. 72, London School of Economics and Political Science, London, UK.

[57] Mankiw, N., R. Reis, and J. Wolfers (2003): "Disagreement about Inflation Expectations" in NBER Macroeconomics Annual, M. Gertler, and K. Rogoff (eds.).

[58] Massaro, D. (2013): "Heterogeneous Expectations in Monetary DSGE Models". Journal of Economic Dynamics and Control 37(3), 680-692.

[59] Pfajfar, D., and E. Santoro (2010): "Heterogeneity, Learning and Information Stickiness in Inflation Expectations". Journal of Economic Behavior and Organization $75(3), 426-444$.

[60] Pfajfar, D., and B. Zakelj (2011): "Inflation Expectations and Monetary Policy Design: Evidence from the Laboratory". CentER Discussion paper \#91.

[61] Roos, M.W.M. and Luhan, W.J. (2012), "Information, learning, and expectations in an experimental model economy". Economica 80(319), 513-531.

[62] Sargent, T.J. (1993): "Bounded Rationality in Macroeconomics: The Arne Ryde Memorial Lectures". Oxford University Press.

[63] Scheinkman, J., and W. Xiong (2003): "Overconfidence and speculative bubbles". Journal of Political Economy 111, 1183-1219.

[64] Shiller, R.J., (2000): "Measuring bubble expectations and investor confidence". Journal of Psychology and Financial Markets 1, 49-60.

[65] Sims, C.A. (1998): "Stickiness". Carnegie-Rochester Conference Series on Public Policy 49, 317-356.

[66] Sims, C.A. (2003): "Implications of Rational Inattention". Journal of Monetary Economics 50(3), 665-690

[67] Simsek A. (2013): "Belief disagreements and collateral constraints". Econometrica 81(1), 1-53.

[68] Sirri, E.R. and Tufano, P., (1998), "Costly search and mutual fund flows". Journal of Finance 53, 1589-1621.

[69] Vissing-Jorgensen, A. (2003), "Perspective on behavioral finance: does "irrationality' disappear with wealth? Evidence from expectations and actions", In: Gertler, M., Rogoff, K. (Eds.) NBER Macroeconomics Annual, MIT Press. 
[70] Westerhoff, F.H. and Reitz, S. (2003), "Nonlinearities and cyclical behavior: the role of chartists and fundamentalists", Studies in Nonlinear Dynamics 8 Econometrics, 7(4). 
1. L. Colombo, H. Dawid, Strategic Location Choice under Dynamic Oligopolistic Competition and Spillovers, Novembre 2013.

2. M. Bordignon, M. Gamalerio, G. Turati, Decentralization, Vertical Fiscal Imbalance, and Political Selection, Novembre 2013.

3. M. Guerini, Is the Friedman Rule Stabilizing? Some Unpleasant Results in a Heterogeneous Expectations Framework, Novembre 2013.

4. E. Brenna, C. Di Novi, Is caring for elderly parents detrimental to women's mental health? The influence of the European North-South gradient, Novembre 2013.

5. F. Sobbrio, Citizen-Editors' Endogenous Information Acquisition and News Accuracy, Novembre 2013.

6. P. Bingley, L. Cappellari, Correlation of Brothers Earnings and Intergenerational Transmission, Novembre 2013.

7. T. Assenza, W. A. Brock, C. H. Hommes, Animal Spirits, Heterogeneous Expectations and the Emergence of Booms and Busts, Dicembre 2013. 